University of Nebraska - Lincoln

DigitalCommons@University of Nebraska - Lincoln

Variability in surface BRDF at different spatial scales (30 m-500 $\mathrm{m}$ ) over a mixed agricultural landscape as retrieved from airborne and satellite spectral measurements

\author{
Miguel O. Román \\ Charles K. Gatebe \\ NASA Goddard Space Flight Center \\ Crystal Schaaf \\ Boston University \\ Rajesh Poudyal \\ NASA Goddard Space Flight Center \\ Zhuosen Wang \\ Boston University \\ See next page for additional authors
}

NASA Goddard Space Flight Center, Miguel.O.Roman@nasa.gov

Follow this and additional works at: https://digitalcommons.unl.edu/nasapub

Part of the Physical Sciences and Mathematics Commons

Román, Miguel O.; Gatebe, Charles K.; Schaaf, Crystal; Poudyal, Rajesh; Wang, Zhuosen; and King, Michael, "Variability in surface BRDF at different spatial scales $(30 \mathrm{~m}-500 \mathrm{~m})$ over a mixed agricultural landscape as retrieved from airborne and satellite spectral measurements" (2011). NASA Publications. 85.

https://digitalcommons.unl.edu/nasapub/85

This Article is brought to you for free and open access by the National Aeronautics and Space Administration at DigitalCommons@University of Nebraska - Lincoln. It has been accepted for inclusion in NASA Publications by an authorized administrator of DigitalCommons@University of Nebraska - Lincoln. 


\section{Authors}

Miguel O. Román, Charles K. Gatebe, Crystal Schaaf, Rajesh Poudyal, Zhuosen Wang, and Michael King 


\title{
Variability in surface BRDF at different spatial scales (30 m-500 m) over a mixed agricultural landscape as retrieved from airborne and satellite spectral measurements
}

\author{
Miguel O. Román ${ }^{\mathrm{a}, *}$, Charles K. Gatebe ${ }^{\mathrm{a}, \mathrm{b}}$, Crystal B. Schaaf ${ }^{\mathrm{c}}$, Rajesh Poudyal ${ }^{\mathrm{a}, \mathrm{d}}$, \\ Zhuosen Wang ${ }^{c}$, Michael D. King ${ }^{\mathrm{e}}$ \\ a Hydrospheric and Biospheric Sciences Laboratory, NASA Goddard Space Flight Center, Greenbelt, MD, USA \\ ${ }^{\mathrm{b}}$ Goddard Earth Sciences and Technology Center, University of Maryland Baltimore County, Baltimore, MD, USA \\ ${ }^{\text {c } D e p t . ~ o f ~ G e o g r a p h y ~ a n d ~ E n v i r o n m e n t, ~ B o s t o n ~ U n i v e r s i t y, ~ B o s t o n, ~ M A, ~ U S A ~}$ \\ d Science Systems and Applications, Inc., Lanham, MD, USA \\ e Laboratory for Atmospheric and Space Physics, University of Colorado, Boulder, CO, USA
}

\section{A R T I C L E I N F O}

\section{Article history:}

Received 25 February 2010

Received in revised form 25 March 2011

Accepted 2 April 2011

Available online 11 May 2011

\section{Keywords:}

BRDF

Surface albedo

Cloud Absorption Radiometer

MODIS

CLASIC'07

ARM Climate Research Facility

US Southern Great Plains

Linear model

Inversion

A priori knowledge

6S

AERONET

Spatial analysis

APU

Airborne measurements

Multiangle remote sensing

EOS land validation core sites

\begin{abstract}
A B S T R A C T
Over the past decade, the role of multiangle remote sensing has been central to the development of algorithms for the retrieval of global land surface properties including models of the bidirectional reflectance distribution function (BRDF), albedo, land cover/dynamics, burned area extent, as well as other key surface biophysical quantities impacted by the anisotropic reflectance characteristics of vegetation. In this study, a new retrieval strategy for fine-to-moderate resolution multiangle observations was developed, based on the operational sequence used to retrieve the Moderate Resolution Imaging Spectroradiometer (MODIS) Collection 5 reflectance and BRDF/albedo products. The algorithm makes use of a semiempirical kernel-driven bidirectional reflectance model to provide estimates of intrinsic albedo (i.e., directional-hemispherical reflectance and bihemispherical reflectance), model parameters describing the BRDF, and extensive quality assurance information. The new retrieval strategy was applied to NASA's Cloud Absorption Radiometer (CAR) data acquired during the 2007 Cloud and Land Surface Interaction Campaign (CLASIC) over the well-instrumented Atmospheric Radiation Measurement Program (ARM) Southern Great Plains (SGP) Cloud and Radiation Testbed (CART) site in Oklahoma, USA. For the case analyzed, we obtained $\sim 1.6$ million individual surface bidirectional reflectance factor (BRF) retrievals, from nadir to $75^{\circ}$ off-nadir, and at spatial resolutions ranging from $3 \mathrm{~m}$ to $500 \mathrm{~m}$. This unique dataset was used to examine the interaction of the spatial and angular characteristics of a mixed agricultural landscape; and provided the basis for detailed assessments of: (1) the use of a land cover type-specific a priori knowledge in kernel-driven BRDF model inversions; (2) the interaction between surface reflectance anisotropy and instrument spatial resolution; and (3) the uncertainties that arise when sub-pixel differences in the BRDF are aggregated to a moderate resolution satellite pixel. Results offer empirical evidence concerning the influence of scale and spatial heterogeneity in kernel-driven BRDF models; providing potential new insights into the behavior and characteristics of different surface radiative properties related to land/use cover change and vegetation structure. Published by Elsevier Inc.
\end{abstract}

\section{Introduction}

Techniques for determining the structure and optical properties of complex heterogeneous environments using multiangle remote sensing are crucial for understanding the effects of environmental change on vegetation structure and thus improve our ability to model terrestrial carbon cycle dynamics and to characterize the ecological functioning of many ecosystems. Recent studies have made considerable progress in developing algorithms for the extraction of quantitative information on terrestrial surface heterogeneity at the subpixel scale (Sandmeier et al., 1998; Widlowski et al., 2001; Pinty et al., 2002; Armston et al., 2007;

\footnotetext{
* Corresponding author. Tel.: +1 301614 5498; fax: +1 3016145269. E-mail address: Miguel.O.Roman@nasa.gov (M.O. Román).
}

Chopping et al., 2008; Hill et al., 2008). In general, this has been achieved by examining how different manifestations of the surface reflectance anisotropy over the angular range are directly related to canopy physiognomy and structure (e.g. canopy height, size, inter-distance between trees, and background vs. foliage contributions).

In the past, previous experiments have generally followed the central assumption that "the potential to detect structural heterogeneity is independent of the spatial scale corresponding to the pixel size" (Pinty et al., 2002). In line with this assumption, earlier studies have treated satellite BRDF/albedo retrievals as being observed over a homogeneous landscape; thus allowing direct "point-to-pixel" comparisons (Hautecoeur \& Leroy, 1998; Liang et al., 2002; Jin et al., 2003a,b; Salomon et al., 2006; Chen et al., 2008; Knobelspiesse et al., 2008; Liu et al., 2009; Rutan et al., 2009). Recent studies have further evaluated surface albedo retrievals both in terms of the spatial 
correspondence (or representativeness) of the field (or tower-based) data and its relationship to the larger satellite pixel (Susaki et al., 2007; Román et al., 2009, 2010). However, because of the impact of view and solar zenith angle (SZA) dependencies, sub-grid scale spatial heterogeneity, and other underlying sources of variation that introduce measurement uncertainties within the ground resolution element (GRE) of satellite retrievals; the BRDF (and thus albedo) of certain ecosystems can only be correctly sampled with airborne multiangle measurements (Walthall et al., 2000). Among key biomes affected by these sources of error are mixed-forest canopies (Johnson, 1994; Russell et al., 1997), tropical savannas (Hill et al., 2008; Georgiev et al., 2009), shrublands (Chopping et al., 2004), as well as snow-covered environments (Lyapustin et al., 2010). Furthermore, recent studies contend that subpixel vegetation structure is only detectable when obtaining measurements near the principal plane; i.e., where BRDF effects are most pronounced (Chen et al., 2005). Consequently, the exact nature of these angular-to-structural relationships has been difficult to quantify at the relevant view-angle geometries of satellite sensors that routinely sample the BRDF over a single overpass (Leroy et al., 1997; Diner et al., 1998b) or in the course of multiple overpasses (Schaaf et al., 2002; Muller et al., 2007).

This study presents a new BRDF/albedo retrieval scheme that uses high quality, multiresolution, and multispectral surface bidirectional reflectance factor (BRF) measurements acquired by NASA's Cloud Absorption Radiometer (CAR) (King et al., 1986; Gatebe et al., 2003). The retrieval strategy, described in Section 2 and tested in Section 3 using data acquired over the well-instrumented Atmospheric Radiation Measurement Program (ARM) Southern Great Plains (SGP) Cloud and Radiation Testbed (CART), is based on the operational Moderate Resolution Imaging Spectroradiometer (MODIS) algorithm for retrieving Surface Reflectance (Vermote et al., 1997; Kotchenova et al., 2006), BRDF and albedo (Schaaf et al., 2002, 2011).

Routine production of land surface BRDF retrievals is often achieved by compiling (or relying on) a global database of archetypal BRDF model reconstructions that seeks to describe the general anisotropic reflectance characteristics of terrestrial ecosystems, at several seasons whenever possible (Bicheron \& Leroy, 2000; Strugnell et al., 2001; Lacaze et al., 2002; Bacour \& Bréon, 2005). The BRDF associated with each location is then assumed to be governed by the character and structure of its land cover (Roujean et al., 1992; Román et al., 2009). In other cases, target-specific BRDF knowledge is used to supplement available observations and improve the quality of a retrieval. For instance, Jin et al. (2002) leveraged the BRDF model parameters derived from Multi-angle Imaging SpectroRadiometer (MISR) surface BRFs to bring additional information to the MODIS retrieval scheme; especially when the MISR observations were close to the principal plane. In either case (i.e., using target-specific or land cover type-specific knowledge), a priori information is being used to indicate when retrieved BRDF model parameters (or albedos) are outside the expected bounds. These approaches are based on Bayesian inference theory, which is considered to be the best way to make use of a priori knowledge to yield a posteriori estimates of unknown BRDF model parameters (Li et al., 2001).

In this study, the new BRDF/albedo retrieval scheme was used to examine the two major assumptions underlying the use of a land cover type-specific a priori knowledge in kernel-driven BRDF models (Lewis, 1995). The first assumption contends that "linear BRDF models can implicitly model surface heterogeneities". The second one argues that "spatial degradation of modeled bidirectional reflectances can be achieved through degradation of the BRDF model parameters". The assumptions were tested in parallel by comparing the relative modelfits (RMS) error from full-inversion retrievals (i.e., high-quality BRDF model inversions obtained directly from CAR measurements) against those that employ an ancillary database of archetypal BRDF model reconstructions to describe the surface anisotropy as either: (1) a linearmixture of different land cover types; or (2) a single (or dominant) land cover type. In all cases, the RMS of relative error was obtained by simulating the surface BRF at the angular sampling of all observations over a given CAR grid cell; thus obtaining error estimates for various spectral bands and spatial scales (cf., Section 4.1).

Because of the difficulties of estimating, validating, and conveying measurement differences between sensors and in-situ measurements, there is also a need to directly examine the accuracy, precision, and uncertainty (APU) of land surface BRDF products; particularly, across complex heterogeneous environments. Accordingly, the interaction between instrument spatial resolution and surface reflectance anisotropy was examined by assessing the distribution of relative differences in surface BRF retrievals obtained from CAR and MODIS BRDF model inversions at different spatial scales and across different spectral regions and view-angle geometries. Finally, the quality of MODIS Collection 5 (MCD43A1) surface BRF retrievals was evaluated across spatial scales to further quantify the uncertainties that arise when sub-pixel differences in the BRDF are aggregated to a moderate resolution satellite pixel ( $c f$. , Section 4.2).

\section{BRDF/albedo retrieval scheme}

The new scheme has three main functional components: atmospheric correction (Fig. 1a), geolocation and gridding (Fig. 1b), and BRDF inversion (Fig. 1c). The aim of atmospheric correction is to retrieve surface-level bidirectional reflectance factor (BRF) measurements from remotely sensed CAR data, which is contaminated by the effects of atmospheric particles and gasses through absorption and scattering of the radiation, especially from the Earth's surface. The aim of geolocation and gridding is to determine the center coordinates of each observation along the instrument scan line (since the CAR data provide only the geolocation of the nadir-looking ground resolution element of each scan), and to register the data to a common grid to maintain consistency across datasets. The aim of BRDF inversion is to fit the RossThickLiSparseReciprocal (RTLSR) BRDF model parameters to surface-level BRF measurements available over each CAR grid cell and spectral band. The retrieval scheme also performs angular integrations to derive intrinsic land surface albedos for each spectral band, and is supported by extensive quality assurance (QA) information.

\subsection{Atmospheric correction}

In the past, various radiative transfer (RT) schemes have been used for the atmospheric correction of CAR data ( $c f .$, Gatebe et al., 2003, 2005; Lyapustin et al., 2010). In this study, we used the second simulation of satellite signal in the solar spectrum (6S) model, version 6SV1.1 (Vermote et al., 1997; Kotchenova et al., 2006), which is the heritage model used in the operational MODIS algorithm for retrieving Surface Reflectance. The 6S code is an RT model based on the successive orders of scattering method. The spectral resolution of the model is $2.5 \mathrm{~nm}$, and the aerosol layer is divided into 13 layers with a scale height of $2 \mathrm{~km}$. The model assumes the atmosphere consists of radioactively active fixed gasses: $\mathrm{O}_{2}, \mathrm{O}_{3}, \mathrm{H}_{2} \mathrm{O}, \mathrm{CO}_{2}, \mathrm{CH}_{4}$, and $\mathrm{N}_{2} \mathrm{O}$. The concentration of $\mathrm{O}_{2}, \mathrm{CO}_{2}, \mathrm{CH}_{4}$, and $\mathrm{N}_{2} \mathrm{O}$ is assumed to be constant and uniformly mixed in the atmosphere. The $6 \mathrm{~S}$ model allows us to determine the attenuation of solar irradiance under cloudless conditions at the surface. It removes the effects of Rayleigh scattering, aerosol attenuation, and ozone and water vapor absorption, provided we know the key characteristics of the atmosphere, such as the atmospheric optical thickness, aerosol model, and absorbing gas concentration. Since the CAR measurements were acquired during intensive field campaigns, coincident and co-located ground-based and airborne data needed as input to the 6S model exist. For example, aerosol parameters can be obtained from groundbased sunphotometer measurements (Holben et al., 1998), or from the Ames Airborne Tracking Sunphotometer (Russell et al., 1999), or retrieved from CAR measurements (Fig. 1a) (Gatebe et al., 2010). 


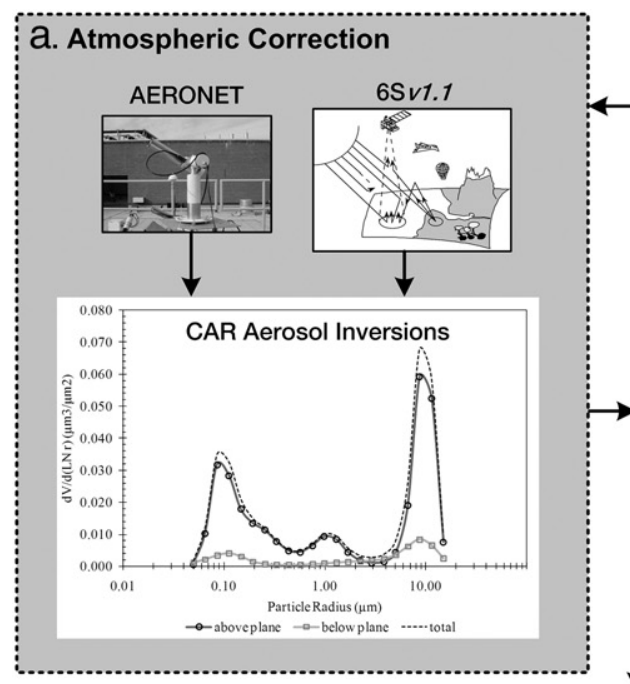

\section{CAR (Level 1B) At-sensor Radiance $L\left(\theta_{\mathrm{s}}, \phi_{\mathrm{s}}, \theta_{\mathrm{v}}, \phi_{\mathrm{v}}, \Lambda\right)$}

\section{b. Geolocation and Gridding}

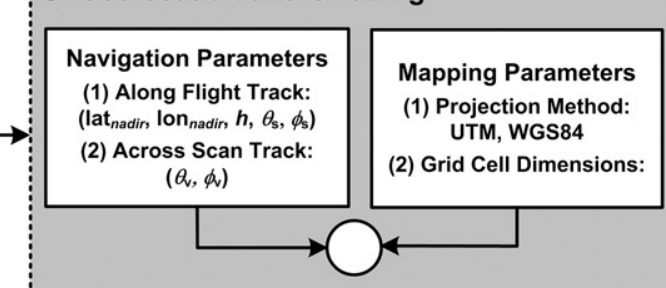

Surface-Level BRF: $\rho\left(\theta_{\mathrm{s}}, \theta_{v}, \Delta \phi\right.$, GIFOV, $\left.\operatorname{Grid}_{[\mathrm{x}, \mathrm{y}]}, \Lambda\right)$

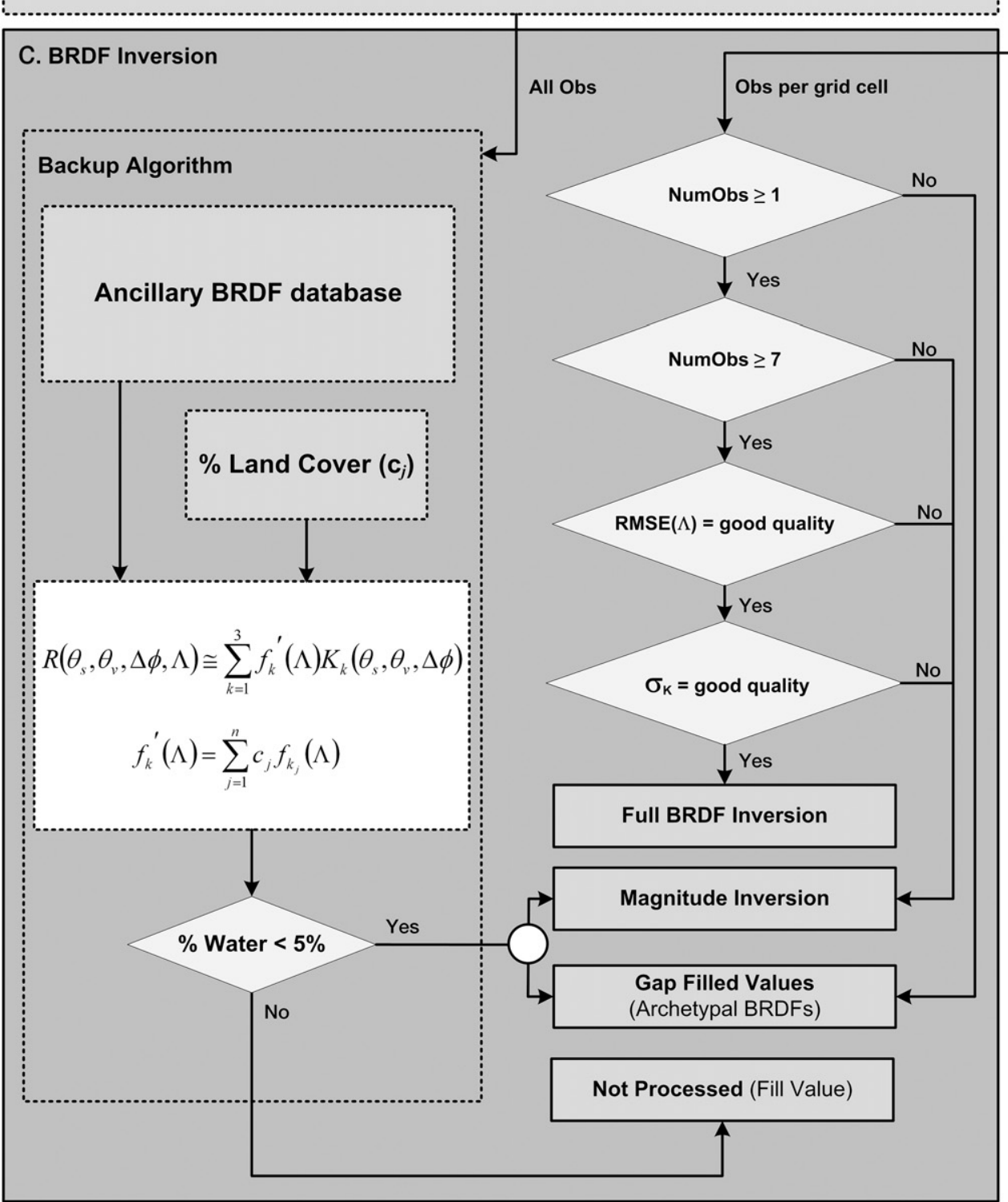

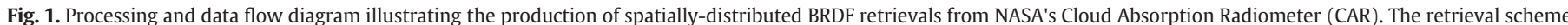
has three main functional components: (a.) atmospheric correction; (b.) geolocation and gridding; and (c.) BRDF inversion. 


\subsection{Geolocation and gridding}

Since the CAR has a wide swath $\left(190^{\circ}\right)$ and an instantaneous field of view (IFOV) of $1^{\circ}$, there is a need to determine the center coordinates of each observation ( lat $_{\text {off-nadir }}$, lon $_{\text {off-nadir }}$ ) along the scan line from nadir to near-horizon (i.e., $0^{\circ} \leq \theta_{v} \leq 75^{\circ}$ ). We used the expression,

lat $_{\text {off-nadir }}=\sin ^{-1}\left[\sin \left(\right.\right.$ lat $\left._{\text {nadir }}\right) \cdot \cos \left[\frac{d}{R_{\otimes}}\right]+\cos \left(\right.$ lat $\left.\left._{\text {nadir }}\right) \cdot \sin \left[\frac{d}{R_{\otimes}}\right] \cdot \cos \left(\phi_{v}\right)\right]$

$\operatorname{lon}_{\text {off-nadir }}=-\left(a-360 \cdot\left\lfloor\frac{a}{360^{\circ}}\right\rfloor\right)+180$

where:

$d=h \tan \left(\theta_{v}\right)$

$a=\operatorname{lon}_{\text {nadir }}-$ dlon $+180^{\circ}$

dlon $=\left\{\begin{array}{l}0 \cos \left(\text { lat }_{\text {nadir }}\right)=0 \\ \psi \cos \left(\text { lat }_{\text {nadir }}\right) \neq 0\end{array}\right\}$

$\psi= \begin{cases}\arctan \left(\frac{y}{x}\right) & x>0 \\ \pi+\arctan \left(\frac{y}{x}\right) & y \geq 0, x<0 \\ -\pi+\arctan \left(\frac{y}{x}\right) & y<0, x<0 \\ \frac{\pi}{2} & y>0, x=0 \\ -\frac{\pi}{2} & y<0, x=0 \\ \text { undefined } & y=0, x=0\end{cases}$

$x=\cos \left[\frac{d}{R_{\otimes}}\right]-\sin \left(\right.$ lat $\left._{\text {nadir }}\right) \cdot \sin \left(\right.$ lat $\left._{\text {off-nadir }}\right)$

$y=\sin \left(\phi_{v}\right) \cdot \sin \left[\frac{d}{R_{\otimes}}\right] \cdot \cos \left(\right.$ lat $\left._{\text {nadir }}\right)$

$d[\mathrm{~km}]$ is the distance from the CAR instrument to the off-nadir target and $R_{\otimes}$ is the earth's radius $\approx 6378.13 \mathrm{~km}$. The size of the CAR's ground resolution element (GRE), [lat $\left.{ }_{\text {nadir }}, \operatorname{lon}_{\text {nadir }}\right]$ is a function of the altitude above ground level $(h)$ as well as IFOV of the instrument $\left(\alpha=1^{\circ} \approx 17.45 \mathrm{mrad}\right)$ :

$G R E=\alpha \cdot h$.

The ground-projected instantaneous field of view (GIFOV) is then calculated based on the relationship:

GIFOV $=h\left[\tan \left(\theta_{v}+\frac{\alpha}{2}\right)-\tan \left(\theta_{v}-\frac{\alpha}{2}\right)\right]$.

Note that the GRE/GIFOV dimensions perpendicular to the azimuth of off-nadir view remain the same. Each location is also referenced to the WGS-84 datum using a "flat earth" approximation.

\subsection{Inversion strategy}

After establishing the geolocation parameters of each CAR observation (i.e., geographic coordinates, GIFOV, and view-solar geometries), BRDF model parameters are then inverted from all available observations on a per grid cell basis. For the BRDF inversion, we adapted the operational Moderate Resolution Imaging Spectroradiometer (MODIS) BRDF/albedo algorithm to fit atmospherically-corrected surface BRF data from CAR at any spectral band. The MODIS algorithm makes use of a linear kernel- based model - the semiempirical reciprocal RossThick-LiSparse (RTLSR) model (Wanner et al., 1995, 1997; Lucht et al., 2000), which takes the form

$$
\begin{aligned}
\operatorname{BRDF}\left(\theta_{s}, \theta_{v}, \Delta \phi, \lambda\right) \cong & R\left(\theta_{s}, \theta_{v}, \Delta \phi, \Lambda\right) \\
= & f_{\text {iso }}(\Lambda)+f_{\text {vol }}(\Lambda) K_{\text {vol }}\left(\theta_{s}, \theta_{v}, \Delta \phi\right) \\
& +f_{\text {geo }}(\Lambda) K_{\text {geo }}\left(\theta_{s}, \theta_{v}, \Delta \phi, P_{4}, P_{5}\right)
\end{aligned}
$$

where:

$$
\begin{aligned}
K_{v o l}= & \frac{(\pi / 2-\xi) \cos \xi+\sin \xi}{\cos \theta_{s}+\cos \theta_{v}}-\frac{\pi}{4} \\
\cos \xi= & \cos \theta_{s} \cos \theta_{v}+\sin \theta_{s} \sin \theta_{v} \cos \Delta \phi \\
K_{\text {geo }}= & \frac{1+\sec \theta_{s}^{\prime} \sec \theta_{v}^{\prime}+\tan \theta_{s}^{\prime} \cos \Delta \phi}{2} \\
& +\left[\frac{t-\sin t \cos t}{\pi}-1\right]\left(\sec \theta_{s}^{\prime}+\sec \theta_{v}^{\prime}\right)
\end{aligned}
$$

$\cos ^{2} t=\min \left\{\left[\frac{P_{4}}{\sec \theta_{v}^{\prime}+\sec \theta_{s}^{\prime}}\right]^{2}\left[D^{2}+\left(\tan \theta_{v}^{\prime} \tan \theta_{s}^{\prime} \sin \Delta \phi\right)^{2}\right], 1\right\}$

$\tan \theta_{x}^{\prime}=P_{5} \tan \theta_{x} ; \quad x=v$ or $s$

$D=\sqrt{\tan ^{2} \theta_{s}^{\prime}+\tan ^{2} \theta_{v}^{\prime}-2 \tan ^{2} \theta_{s}^{\prime} \tan _{v}^{\prime} \cos \Delta \phi}$

where the wavelength for the narrowband instruments of interest is here defined over the waveband $\Lambda$ with limits $\left[\Lambda_{\min }, \Lambda_{\max }\right]$. BRDF parameter (or kernel weight) $f_{\text {iso }}(\Lambda)$ is the isotropic scattering component and equivalent to a nadir-view $\left(\theta_{v}=0\right)$, zenith-sun $\left(\theta_{s}=0\right)$ reflectance retrieval. Parameter $f_{\text {geo }}(\Lambda)$ is the coefficient of the LiSparse-Reciprocal geometric scattering kernel $K_{\text {geo }}$, derived for a sparse ensemble of surfaces casting shadows on a Lambertian background (Li \& Strahler, 1992). Parameter $f_{\text {vol }}(\Lambda)$ is the coefficient for the RossThick volume scattering kernel $K_{v o l}$, so called for its assumption of a dense leaf canopy (Ross, 1981). $\Delta \phi$ is the relative azimuth angle $\left(\Delta \phi=\phi_{s}-\phi_{v}\right)$ (where subscript $s$ and $v$ denote solar and view azimuth, respectfully) and $\xi$ is the scattering (or phase) angle between sun and view directions. The variable $h$ is the mean height at which a crown center is located, $b$ is the mean vertical halfaxis of the modeled ellipsoid, and $r$ is the mean horizontal radius. Based on previous experiments, the dimensionless crown relative height $\left(P_{4}=h / b\right)$ and shape $\left(P_{5}=b / r\right)$ parameters (both mean values) have been fixed at $h / b=2$ and $b / r=1$ to invert the angular radiance data from MODIS (Wanner et al., 1995; Privette et al., 1997).

In order to invert Eq. (11) for given reflectance observations $\rho\left(\theta_{s}^{i}, \theta_{v}^{i}\right.$, $\left.\Delta \phi^{i}, \Lambda\right)(i=1, \ldots, n)$ over a given grid cell, we need to minimize $\delta \mathrm{e}^{2} / \delta f_{k}(\Lambda)$ of a least squares error function

$e^{2}=\frac{1}{n-3} \sum_{i=1}^{n} \frac{\left(\rho\left(\theta_{s}^{i}, \theta_{v}^{i}, \Delta \phi^{i}, \Lambda\right)-R\left(\theta_{s}^{i}, \theta_{v}^{i}, \Delta \phi^{i}, \Lambda\right)\right)^{2}}{w_{i}(\Lambda)}$

to establish the analytical solution for the RLTSR BRDF model parameter values $f_{k}(\Lambda)$,

$$
\begin{aligned}
f_{k}(\Lambda)= & \sum_{i=1}^{3}\left\{\sum_{j=1}^{n} \frac{\rho\left(\theta_{s}^{j}, \theta_{v}^{j}, \Delta \phi^{j}, \Lambda\right) K_{i}\left(\theta_{s}^{j}, \theta_{v}^{j}, \Delta \phi^{j}, \Lambda\right)}{w_{j}(\Lambda)}\right. \\
& \left.\times\left(\sum_{l=1}^{n} \frac{K_{i}\left(\theta_{s}^{l}, \theta_{v}^{l}, \Delta \phi^{l}, \Lambda\right) K_{k}\left(\theta_{s}^{l}, \theta_{v}^{l}, \Delta \phi^{l}, \Lambda\right)}{w_{l}(\Lambda)}\right)^{-1}\right\}
\end{aligned}
$$


where $w_{j}(\Lambda)$ is the weight for the $j$ th observation at waveband $\Lambda$. For any given CAR retrieval scenario, a full BRDF model inversion is attempted if at least 7 observations are available. Each observation is evaluated to discard outliers and additional checks are performed to assure that the RTLSR kernel weights are positive. The use of positive kernel weights, a constraint that is generally adopted in kernel-driven BRDF model inversions (Chopping, 2001; Schaaf et al., 2002), provides increased confidence that the functions are representing (through stable bowlshape vs. bell-shape surface anisotropy features) the biophysical processes they seek to describe. Thus, if RTLSR routinely produces positive kernel weights, then it could be considered to be operating in a semiphysical mode. Otherwise, the model could be considered to be operating in a purely empirical mode (i.e., the kernels just provide arbitrary curves since they are no longer constrained by the physics) (Chopping, 2011, pers. comm.) Previous studies have favored the RossThin-LiSparse kernel combination (Roujean et al., 1992; Wanner et al., 1995) over arid/semiarid environments, because it results in less instances of negative kernel weights relative to RTLSR (Su et al., 2007). On a global basis, the use of positive RTLSR kernel weights is also preferred (Privette et al., 1997); particularly in situations where more physically-based quantities are directly derived from the BRDF model parameters. These include intrinsic spectral albedos (i.e., bi-hemispherical reflectance or white-sky albedo) (Martonchik et al., 2000; Schaepman-Strub et al., 2006), foliage clumping index (CI) (Chen et al., 2005), top-of-canopy vegetation indexes (i.e., NDVI and EVI) (Tucker, 1979; Huete et al., 2002) derived from Nadir BRDF-
Adjusted Reflectances (NBAR) (Schaaf et al., 2002), and BRDF shape indicators (i.e., a set of angular indexes developed to indicate BRDF shape in MODIS data) (Hill et al., 2008).

Fig. 2 illustrates the shapes of the RossThick $\left(K_{v o l}\right)$ and LiSparseReciprocal $\left(K_{\text {geo }}\right)$ kernels, based on the CAR atmospherically-corrected BRF data from the CART site, described in Section 3. Note that the behavior of the two kernels is different in nature over the full angular range of CAR observations. While they are not perfectly orthogonal functions, $K_{v o l}$ and $K_{\text {geo }}$ are sufficiently independent to allow for a stable recovery of the RTLSR kernel weights for many viewing and illumination conditions. The absence of excessive kernel-to-kernel correlation is key to reliable BRDF model inversions (Lucht et al., 2000).

Finally, the absolute model-fits error (RMS or RMSE),

$R M S$ of absolute error $(\Lambda)=\sqrt{\frac{\sum_{i=1}^{n}\left(\rho\left(\theta_{s}^{i}, \theta_{v}^{i}, \Delta \phi^{i}, \Lambda\right)-R\left(\theta_{s}^{i}, \theta_{v}^{i}, \Delta \phi^{i}, \Lambda\right) \times w_{i}(\Lambda)\right)^{2}}{n-3}}$

where $w_{i}(\Lambda)$ is the weight for the $i$ th observation at waveband $\Lambda$. The weights are applied using a Gaussian-threshold model defined by

$w_{i}(\Lambda)=p_{i}(\Lambda) \times s_{i}(\Lambda)$
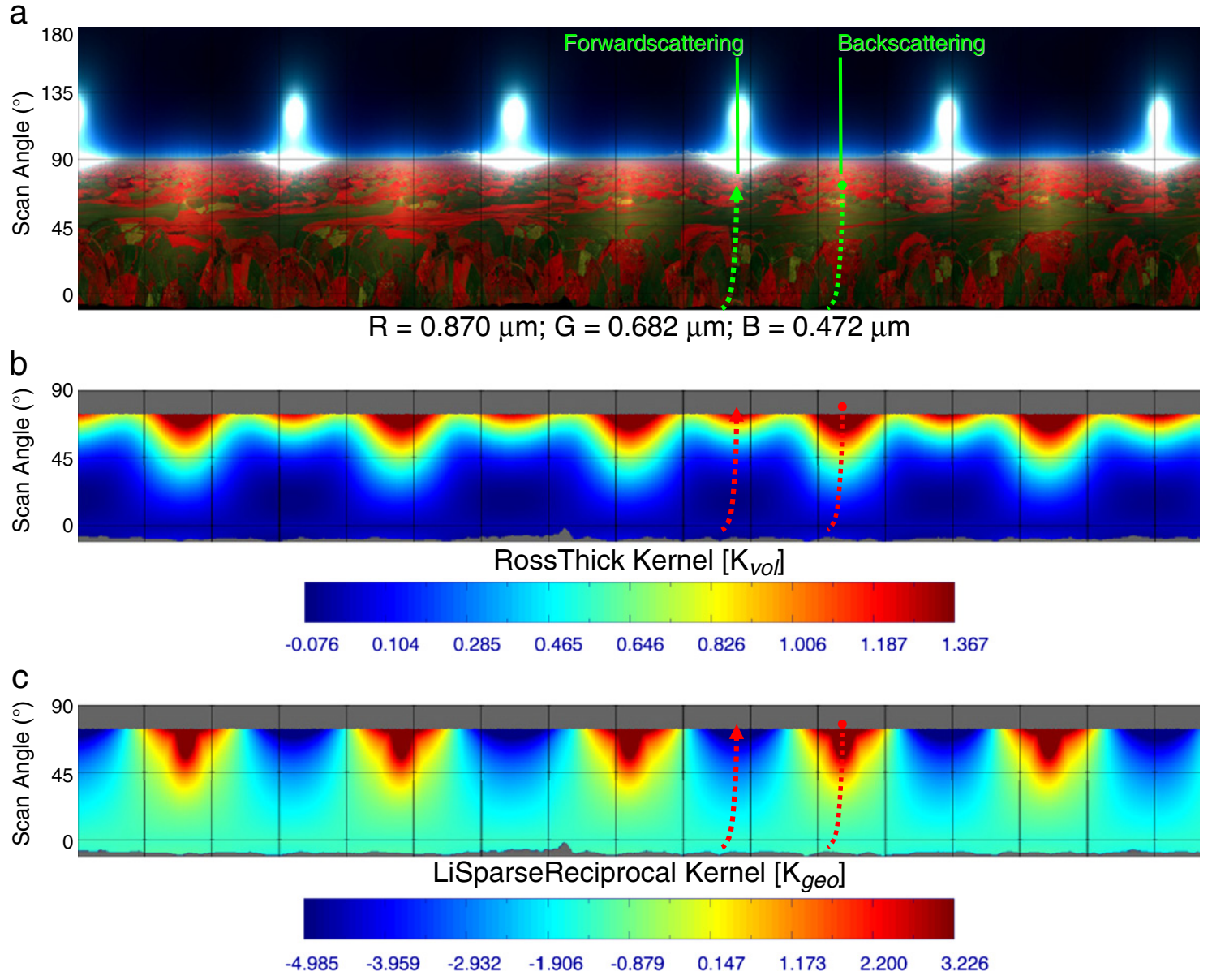

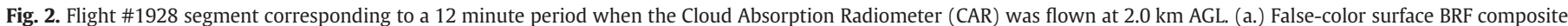

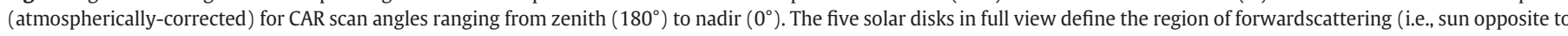

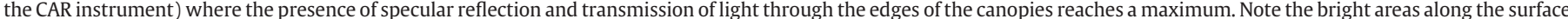

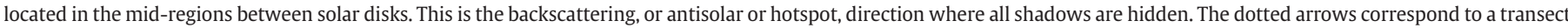

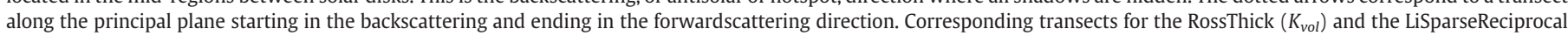
$\left(K_{\text {geo }}\right)$ kernels (b. and c., respectively) are also shown. 
where,

$$
\begin{aligned}
& p_{i}(\Lambda)=e^{-\frac{\Delta \phi^{2}}{2 c^{2}}}+e^{-\frac{\left(180^{\circ}-\Delta \phi\right)^{2}}{2 c^{2}}} \\
& s_{i}(\Lambda)=e^{-\frac{(\text { GIFOV-scale })^{2}}{2 d^{2}}} \\
& c=45^{\circ} ; d=\text { scale } / 3.0
\end{aligned}
$$

The first weight, $p_{i}(\Lambda)$, depends on the adequacy of the angular sampling across the solar azimuth region or principal plane, where the surface reflectance anisotropy is more sensitive to canopy biophysical characteristics (Privette et al., 1996; Bacour et al., 2002). The second weight, $s_{i}(\Lambda)$, depends on the degree of spatial correspondence (or representativeness) between the ground-projected instantaneous field of view (GIFOV) and the scale (or grid cell size) being selected (Román et al., 2009). Both $p_{i}(\Lambda)$ and $s_{i}(\Lambda)$ seek to adjust the relative influence of each observation while preserving the spatial and angular sampling characteristics of each retrieval. Thus, when combined, these weights produce retrievals that are more sensitive to variability in the structural characteristics of different heterogeneous landscapes.

The degree of angular sampling is determined by computing the overall spread or dispersion, $\sigma_{K}$, of the RTLSR kernels

$$
\sigma_{K}=\left[\frac{\sum_{i=1}^{n}\left(K_{v o l}(i)-\bar{K}_{v o l}\right)^{2}}{n-1}+\frac{\sum_{i=1}^{n}\left(K_{g e o}(i)-\bar{K}_{g e o}\right)^{2}}{n-1}\right]
$$

Since the RTLSR kernels provide different geometric expressions for a particular type of BRDF, it should follow that the larger the spread $\left(\sigma_{K}\right)$, the more adequate the angular sampling under a given sun-view geometry.

Both the RMS of absolute error and $\sigma_{\mathrm{K}}$ are computed to establish retrieval confidence. Only if the observations pass all of these evaluations is a full inversion performed to establish the RTLSR kernel weights that provide the 'best fit' estimate. For those cases with insufficient observations $(i<7)$, or a poor fit, (i.e., RMS of absolute error $>0.02$ for $\Lambda=0.472 \mu \mathrm{m}$; $>0.04$ for $\Lambda=0.682 \mu \mathrm{m}$; $>0.09$ for $\Lambda=0.870 \mu \mathrm{m}$; and $>0.08$ for $\Lambda=1.219 \mu \mathrm{m}$ ), a magnitude inversion is performed rather than a full model inversion. Note that, unlike the MODIS magnitude inversion strategy over snow-free environments (which leverages a global database of archetypal anisotropic models of MODIS-derived representation of seasonal BRDF), this retrieval scheme reutilizes the CAR BRDF retrievals obtained during the same flight period to process those areas where a full retrieval couldn't be made. An ancillary database derived from high-quality, coincident, and co-located surface BRDF data is then parameterized with area-based proportions of land cover type to obtain a set of archetypal BRDF shapes (cf., Section 3). Consequently, by assuming that surface BRFs scale linearly in a spatial sense (Lewis, 1995), a full range of mixed BRDF patterns can be reconstructed using the following equation:

$R\left(\theta_{s}, \theta_{v}, \Delta \phi, \Lambda\right) \cong \sum_{k=1}^{3} f_{k}^{\prime}(\Lambda) K_{k}\left(\theta_{s}, \theta_{v}, \Delta \phi\right)$

where

$f_{k}^{\prime}(\Lambda)=\sum_{j=1}^{n} c_{j} f_{k_{j}}(\Lambda)$

and $c_{j}$ is the proportional weight of each land cover type $(j=1, \ldots, n)$ within a given CAR grid cell. Accordingly, magnitude inversions were supported by a "first-guess" estimate of the general BRDF shape for a spatially heterogeneous landscape, and then constrained by the available observations. With the exception of water-contaminated regions, gapfilled retrievals were also obtained for areas without available observa- tions. Finally, spatially-distributed (or gridded) fields, each defined by a distinct cell size and GIFOV range, are generated. The end result is a series of multiscale BRDF retrievals derived explicitly from the CAR instrument.

\subsubsection{Albedo retrieval}

Once appropriate RossThick-LiSparseReciprocal (RTLSR) BRDF model parameters have been retrieved, the directional-hemispherical reflectance (DHR), or black-sky albedo (BSA), are computed at any desired solar zenith angle by integration over all view zenith angles. A further integration over all illumination angles results in a bihemispherical reflectance (BHR), or white-sky albedo (WSA), under isotropic illumination. These two quantities can be determined from Eqs. (28) and (29):

$$
\begin{aligned}
& B S A\left(\Lambda, \theta_{s}\right)=\sum_{k} f_{k}(\Lambda) \cdot h_{k}\left(\theta_{S}\right) \\
& W S A(\Lambda)=\sum_{k} f(\Lambda)_{k} \cdot H_{k}
\end{aligned}
$$

where: $h_{k}\left(\theta_{s}\right)$ is the integral of the BRDF model kernels $k$ over a given view zenith and view-sun relative azimuth angle; $H_{k}$ is the integral of $h_{k}$ over a given solar zenith angle $\theta_{s}$; and $f_{k}(\Lambda)$ are the BRDF kernel model parameters $k$. It should be noted that the black-sky and white-sky albedo quantities are intrinsic to a specific location and are governed by the character and structure of its land cover (Schaaf et al., 2008).

The CAR retrieval scheme can be extended to acquire other multi-view angle data of interest to studies of the photosynthetic and structural characteristics of vegetation covers and their phenological state (e.g., Nadir BRDF-Adjusted Reflectances and BRDF shape indicators). For the purposes of this study, however, only surface BRF retrievals (i.e., obtained from inversion of RTLSR BRDF model parameters) were examined. We can now look at the measurements used to test the new retrieval scheme.

\section{Measurements}

The CAR data were selected from the Cloud and Land Surface Interaction Campaign (CLASIC), an extensive field campaign conducted in the summer of 2007 in Oklahoma and Kansas with a primary emphasis on the US Southern Grain Plains (SGP; Fig. 3a). The intense observing period was from June 9 to 30, 2007 based out of Ponca City, Oklahoma. In addition to the large-scale soil moisture measurements conducted throughout the CLASIC experiment, land cover surveys, vegetation measurements, and surface characterizations were also conducted to develop detailed vegetation water content and land cover imagery (Cosh, 2007). These records were combined with medium-to-high spatial resolution multispectral satellite imagery - i.e., a $2.4 \mathrm{~m}$ IKONOS scene (GeoEye, 2006), three Landsat $30 \mathrm{~m}$ scenes and eight Advanced Wide Field Sensor (AWiFS) $56 \mathrm{~m}$ scenes (NRSA, 2003) - to create a $10 \mathrm{~km}^{2}$ land cover map with an overall classification accuracy of 92\% (relative to ground surveys; Fig. 4a). The effective spatial resolution of the CLASIC land cover map is $2.4 \mathrm{~m}$; although it includes surface characterizations collected at $30 \mathrm{~m}$ and $56 \mathrm{~m}$, as well as polygon datasets extracted from coincident and previous field studies (Trishchenko et al., 2005). The total number of classes was reduced by 10 , according to survey results acquired during the period coinciding with the CAR measurements.

Onboard the Jetstream-31 aircraft, the CAR instrument was used to acquire multiangular and multispectral observations under different sky conditions (Fig. 5a and b). Flights were designed to cover four major surface conditions across the SGP, including crops, bare soils, and pasture at the CART site, $36.60^{\circ} \mathrm{N}, 97.48^{\circ} \mathrm{E}$, grasslands at the Little Washita Watershed, $35.044^{\circ} \mathrm{N}, 97.914^{\circ} \mathrm{W}$, irrigated crops at the Fort Cobb Watershed, $35.15^{\circ} \mathrm{N},-98.47^{\circ} \mathrm{E}$, and broadleaf deciduous canopies at the Forest Site, $35.615^{\circ} \mathrm{N},-96.07^{\circ} \mathrm{E}$ ) (Cosh, 2007). The present study focuses on an intense observing period during the CLASIC experiment surrounding the CART site, which is heavily 

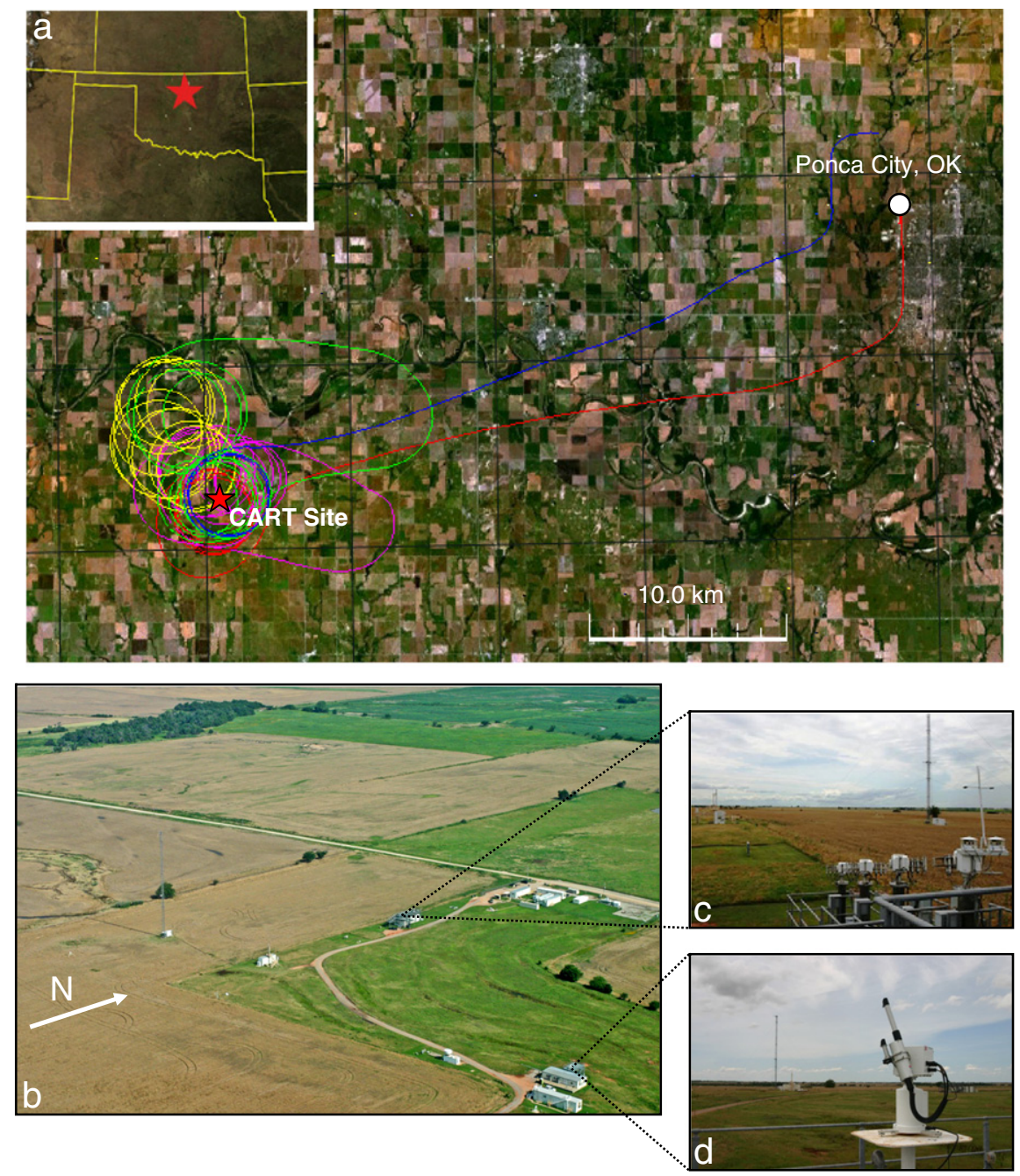

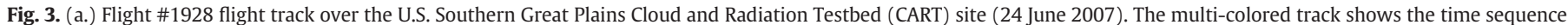

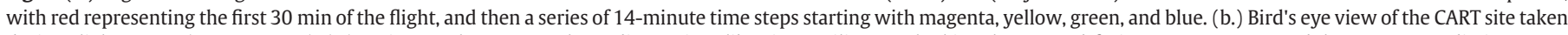

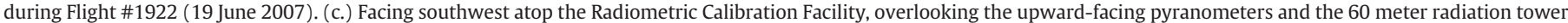
(20 June 2007). (d.) Facing west atop the Guest Instrument Facility, overlooking the AERONET sun photometer (20 June 2007).

instrumented and dominated by cattle pasture, bare soils, and winterwheat fields ( $c f .$, Fig. 3).

To acquire BRDF measurements, the aircraft flew a clockwise circular pattern above the surface (Fig. 5c) repeatedly, and at different altitudes ranging from $\sim 0.2$ to $<8 \mathrm{~km}$. At an aircraft bank angle of $20^{\circ}$, the plane takes roughly 2-3 min to complete a circular path (or orbit). Among the unique features of the CAR is the fact that the instrument observes the reflected solar radiation at a fine angular resolution defined by an instantaneous field of view of $1^{\circ}$. It is normally set to scan from nadir all the way to the zenith (cf., Fig. 2a), but can also be set to observe the entire downwelling scattered radiation field at approximately half-degree intervals through its $190^{\circ}$ aperture at a rate of 100 scans per minute. Therefore, the CAR collects between 76,400 and 114,600 directional measurements of radiance per channel per complete orbit, which amounts to between 687,600 and $1,031,400$ measurements per orbit for nine channels.

We selected the J-31 flight on 24 June 2007, Flight \# 1928, over the CART site because of favorable clear-sky conditions. This was an earlymorning flight (12:57 to 14:44 UTC). A complete description of this and other CAR flights, including flight summaries (i.e., path, timing, and measurements, imagery, and mission details) can be found on the CAR web site (http://car.gsfc.nasa.gov/). Angular measurements were taken at several heights above ground level (i.e., $200 \mathrm{~m}, 600 \mathrm{~m}$, $2000 \mathrm{~m}$, and $\sim 4000 \mathrm{~m}$ ). This resulted in 1,619,543 individual BRDF measurements at view zenith angles from nadir to $75^{\circ}$ off-nadir, and at spatial resolutions ranging from $3 \mathrm{~m}$ to $500 \mathrm{~m}$. We performed atmospheric correction using each observation's unique viewing (i.e., $0^{\circ} \leq \Delta \phi \leq 180^{\circ} ; 0^{\circ} \leq \theta_{v} \leq 75^{\circ}$ ) and illumination geometries (i.e., $48^{\circ} \leq \theta_{s} \leq 72^{\circ}$ ), under a non-Lambertian surface, and for corresponding height above ground level (i.e., from $0.2 \mathrm{~km}$ to $4.0 \mathrm{~km}$ ). Other quantities used for the RT calculations include: (1) total column $\tau_{0.55 \mu \mathrm{m}}=0.150(0.141$ above the aircraft when flying at $\sim 0.2 \mathrm{~km}$ above the surface); (2) total column $\mathrm{H}_{2} \mathrm{O}=1.42 \mathrm{~g} \mathrm{~cm}^{-2}\left(0.62 \mathrm{~g} \mathrm{~cm}^{-2}\right.$ above the aircraft); and (3) ozone column amount $\mathrm{O}_{3}=344 \mathrm{DU}$.

A database of archetypal BRDF shapes derived from Flight \#1928 measurements, and parameterized with land cover data, was also created. This was achieved by: (1) deriving GIFOV-specific values of percent land cover by using the CLASIC land cover map as the base layer; (2) extracting those observations that formed a single (or dominant) surface condition; and (3) averaging those remaining measurements that were acquired at $\pm 15^{\circ}$ off the principal plane and observed under the similar view-solar conditions (i.e., $\pm 1^{\circ}$ ). We defined dominant surface conditions as those with a fractional cover of $\geq 75 \%$ and we limited water-contaminated areas to $<5 \%$. To the 
a
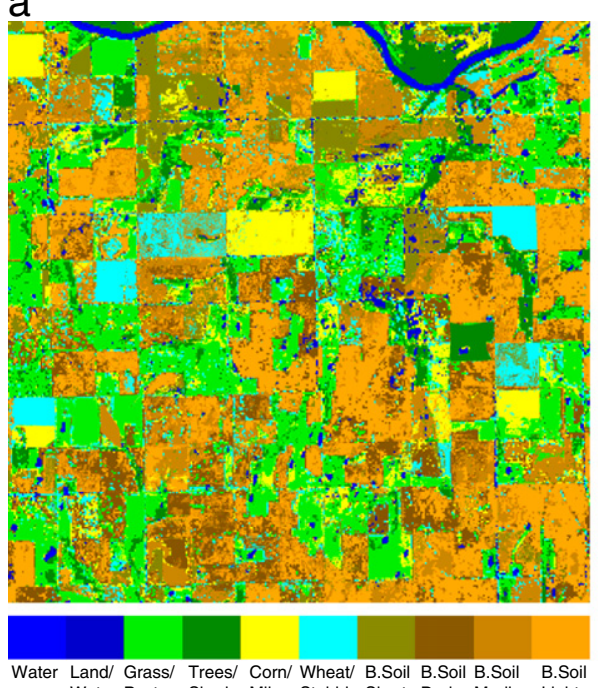
ark Medium Light Mix b

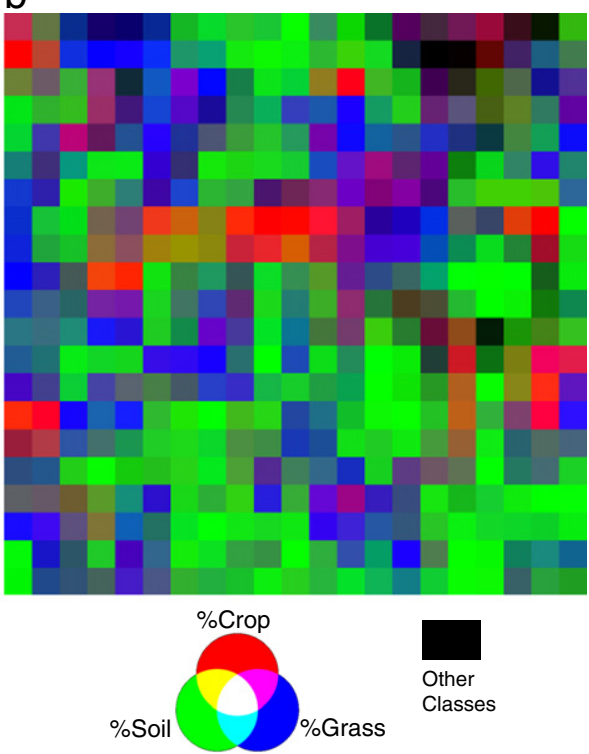

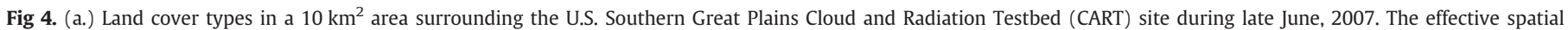

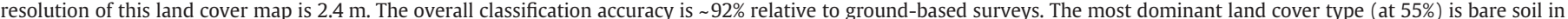

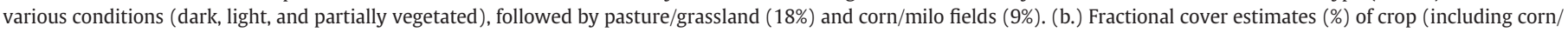
milo and wheat/stubble classes), pasture, and bare soils, using a $500 \mathrm{~m}$ grid cell size.
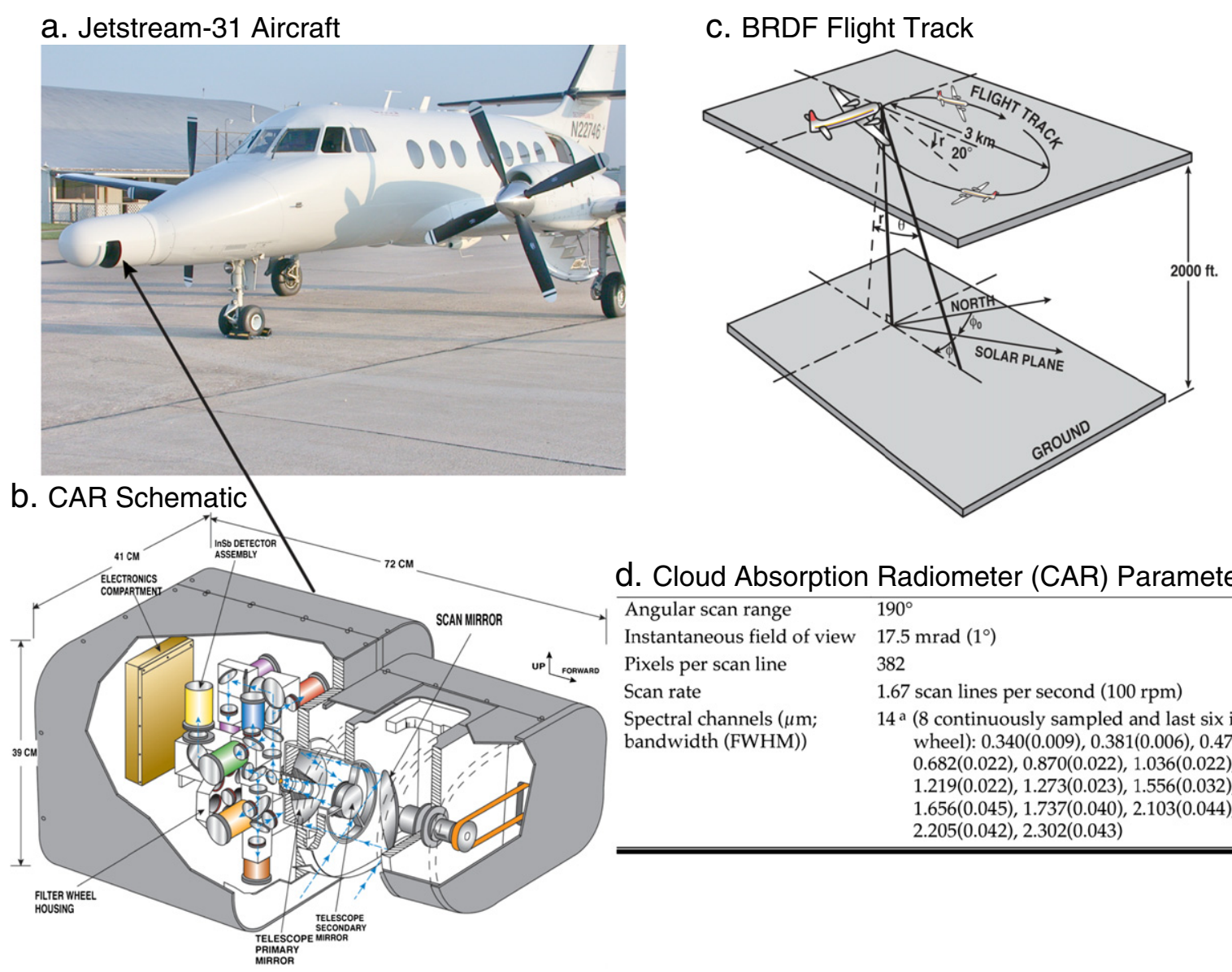

d. Cloud Absorption Radiometer (CAR) Parameters Angular scan range $190^{\circ}$

Instantaneous field of view $17.5 \mathrm{mrad}\left(1^{\circ}\right)$

Pixels per scan line $\quad 382$

Scan rate

1.67 scan lines per second ( $100 \mathrm{rpm})$

Spectral channels $(\mu \mathrm{m} ; \quad 14 \mathrm{a}$ ( 8 continuously sampled and last six in filter bandwidth (FWHM))

wheel): $0.340(0.009), 0.381(0.006), 0.472(0.021)$, $0.682(0.022), 0.870(0.022), 1.036(0.022)$, $1.219(0.022), 1.273(0.023), 1.556(0.032)$ $1.656(0.045), 1.737(0.040), 2.103(0.044)$, 2.205(0.042), 2.302(0.043)

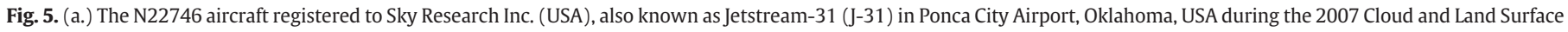

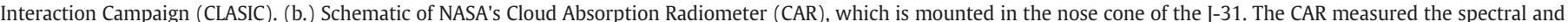

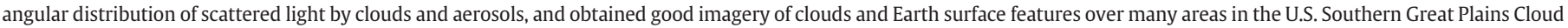

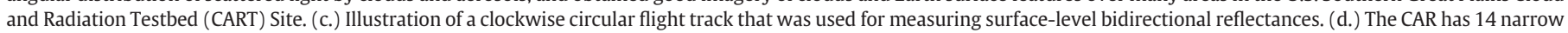
spectral bands between 0.34 and $2.30 \mu \mathrm{m}$, and flew 11 missions during CLASIC (King et al., 1986; Gatebe et al., 2003). 

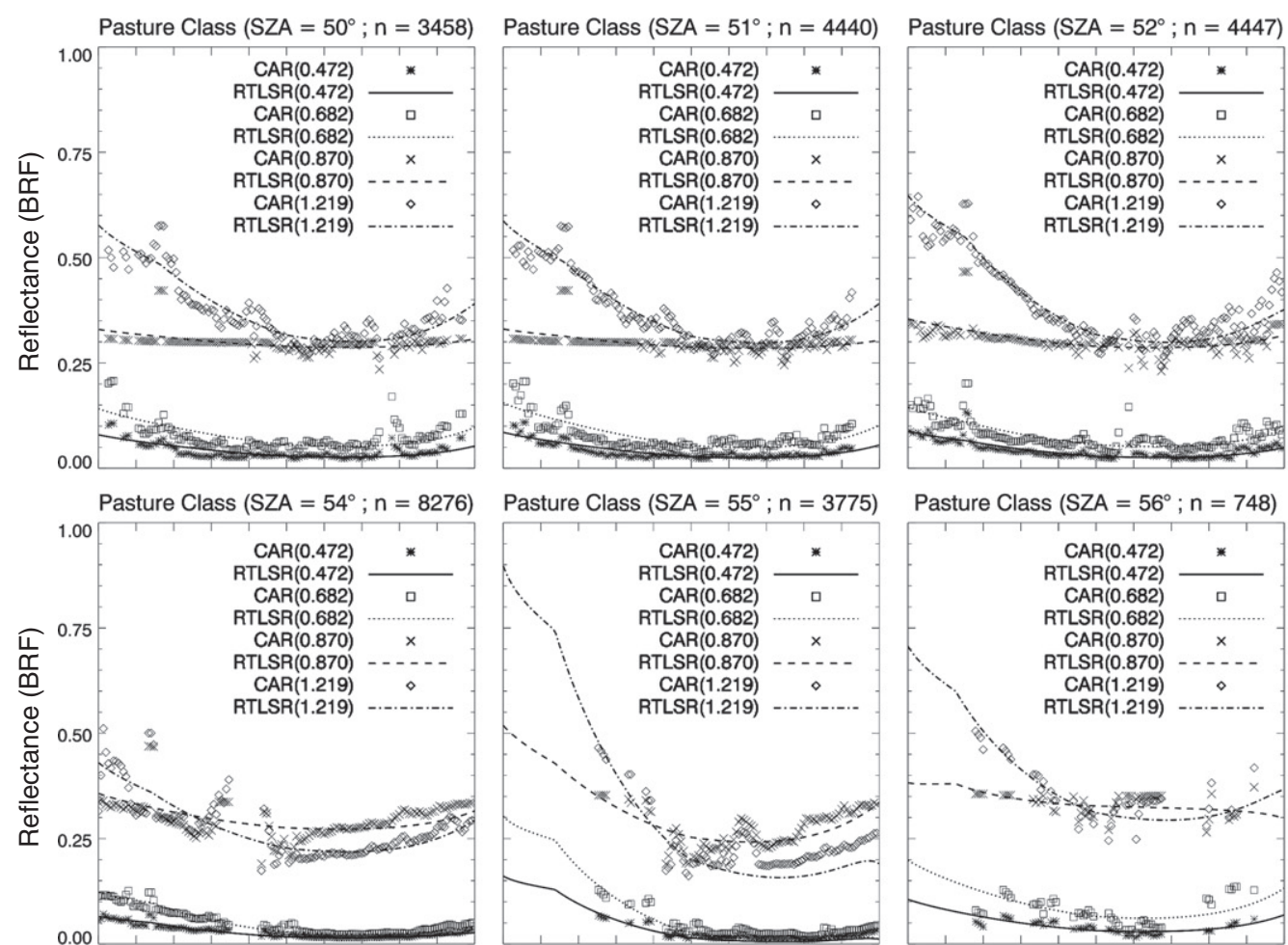

Pasture Class $\left(\mathrm{SZA}=55^{\circ} ; \mathrm{n}=3775\right)$

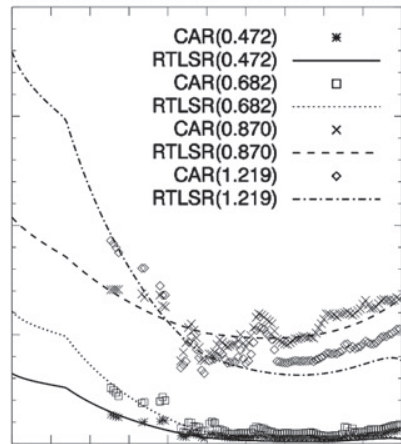

Pasture Class $\left(\mathrm{SZA}=59^{\circ} ; \mathrm{n}=2367\right)$
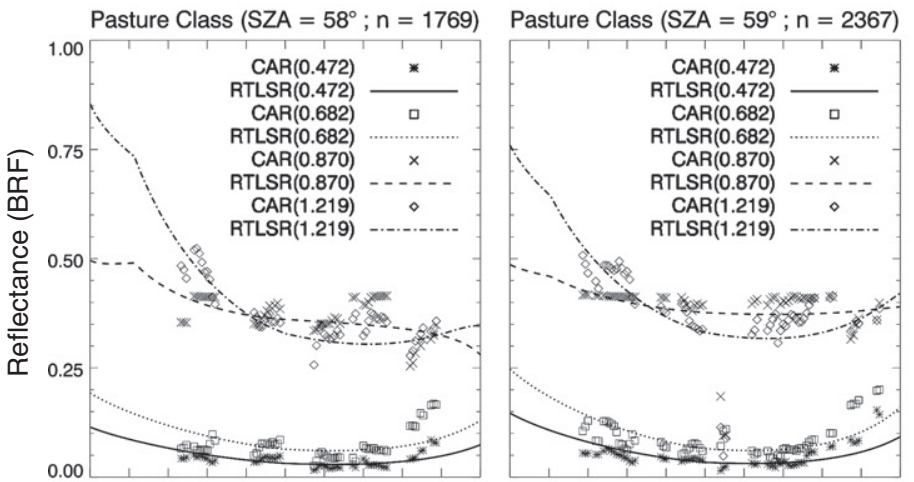

Pasture Class $\left(\mathrm{SZA}=63^{\circ} ; \mathrm{n}=4296\right)$
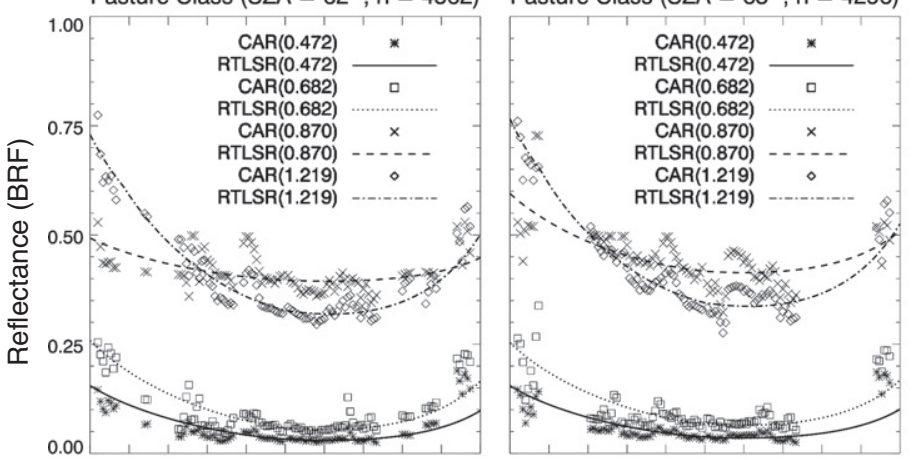

Pasture Class $\left(\mathrm{SZA}=56^{\circ} ; n=748\right)$

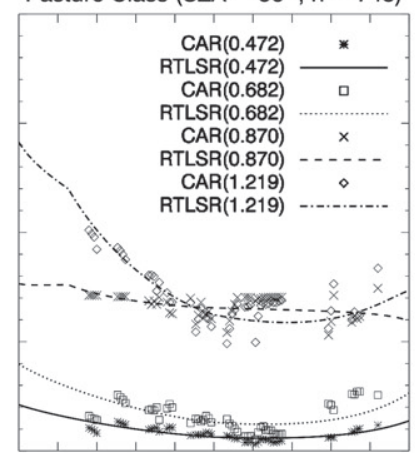

Pasture Class $\left(\mathrm{SZA}=60^{\circ} ; n=2943\right)$
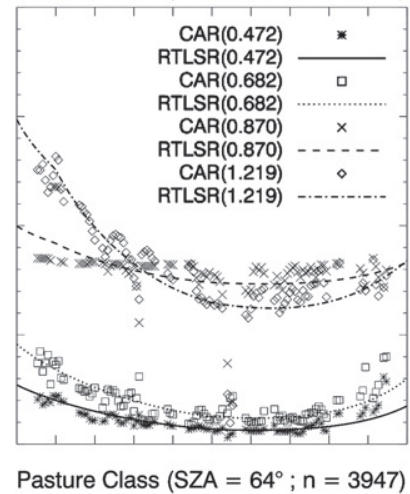

Pasture Class $\left(\mathrm{SZA}=53^{\circ} ; \mathrm{n}=7695\right)$

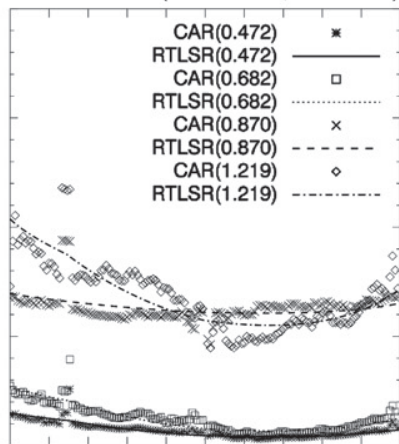

Pasture Class $\left(\mathrm{SZA}=57^{\circ} ; \mathrm{n}=749\right)$

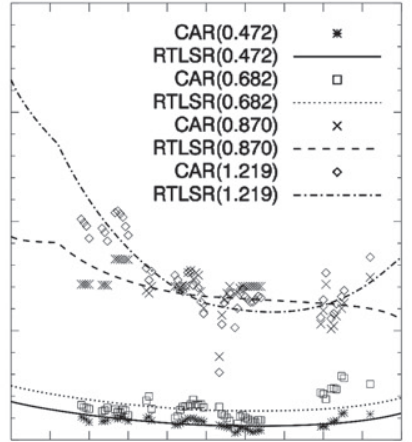

Pasture Class $\left(\mathrm{SZA}=61^{\circ} ; \mathrm{n}=4245\right)$
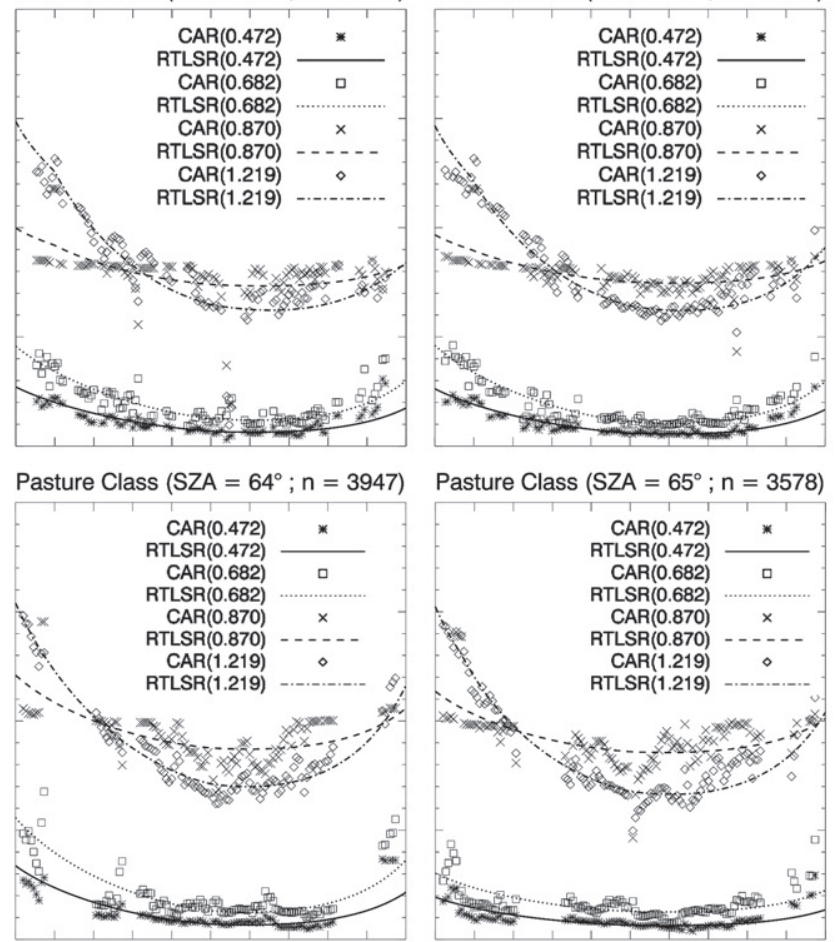

Pasture Class $\left(\mathrm{SZA}=65^{\circ} ; \mathrm{n}=3578\right)$

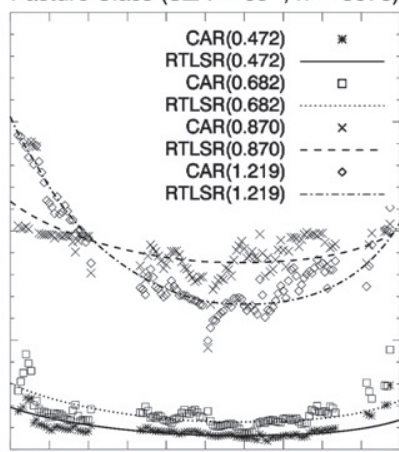

$\begin{array}{llllllllllllllllllllllllllllllllllllllllllllllllllllll}-75 & -60 & -45 & -30 & -15 & 0 & 15 & 30 & 45 & 60 & 75 & -75 & -60 & -45 & -30 & -15 & 0 & 15 & 30 & 45 & 60 & 75 & -75 & -60 & -45 & -30 & -15 & 0 & 15 & 30 & 45 & 60 & 75 & -75 & -60 & -45 & -30 & -15 & 0 & 15 & 30 & 45 & 60 & 75\end{array}$ Principal Plane View Zenith Angle $\left(^{\circ}\right)$

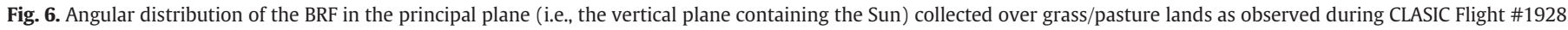

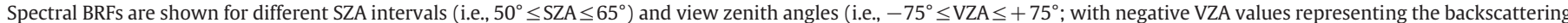

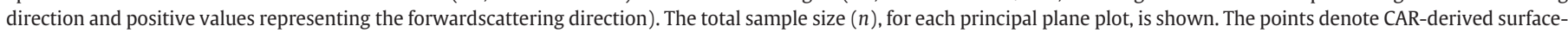

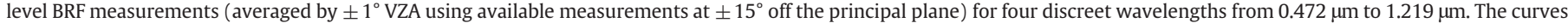
show the respective spectral BRFs obtained from RTLSR BRDF model inversions.

extent possible, areas comprised by 'water' and 'land/water mix' classes ( $c f .$, Fig. 4a) were excluded from this analysis. This was done to reduce classification errors associated with changing weather condi- tions (e.g., rainfall events). The observations that passed the abovementioned screening tests were then used to invert the RTLSR kernel weights and obtain the lowest RMS of absolute error. 
Unlike the surface Bidirectional Reflectance Factor, $R\left(\theta_{s}, \theta_{v}, \Delta \phi ; \Lambda\right)$, the RLTSR kernel weights do not depend on view-solar geometry. Therefore, a series of high-quality BRDF model inversions based on observations from a dominant surface condition (but for different illumination conditions) should generate similar, if not identical weights. Under this premise, BRDF model parameters acquired using the abovementioned screening process were used to calculate the weighted average (based on the band-specific RMS of absolute error) for each representative land cover class identified across the CART site during the CLASIC experiment (Fig. 4a). Note that unlike the RMS of absolute error obtained through routine inversions of RTLSR (i.e., full and magnitude inversions), the archetypal BRDF database is not weighted by observation quality (i.e., $w_{i}(\Lambda)=1.0$ ); although the screening process is indirectly used to constrain the observations. The resulting spectral BRF measurements from CAR and their respective 'best-fit' results from RTLSR model inversion are illustrated for two land cover classes (i.e., grass/pasture and light bare soils) in Figs. 6 and 7. Table 1 presents the resulting RTLSR kernel coefficients for each of the representative land cover types identified across the CART site during the CLASIC experiment.

Spatially-distributed BRDF retrievals were derived from the Flight \#1928 RossThick-LiSparseReciprocal (RTLSR) model parameters using three different grid sizes. Fig. 8 illustrates the results for a $10 \mathrm{~km}^{2}$ area surrounding the CART site. Different panels represent the RTLSR kernel weights, $f_{\text {iso }}(\Lambda), f_{\text {vol }}(\Lambda)$, and $f_{\text {geo }}(\Lambda)$, for CAR channels $\Lambda=0.682 \mu \mathrm{m}$ (Fig. 8a) and $\Lambda=0.870 \mu \mathrm{m}$ (Fig. 8b). Each retrieval is defined by a distinct cell size (or spatial scale) and ground-projected instantaneous field of view (GIFOV) range. The three sampling intervals (i.e., $30 \mathrm{~m}, 60 \mathrm{~m}$, and $240 \mathrm{~m}$ ) were selected on the basis of how CAR measurements obtained at different GIFOVs were observed similarly in terms of angular sampling. This is demonstrated in Fig. 9, which shows the distribution of surface-level BRFs from Flight \#1928 as a function of GIFOV, view zenith angle, solar zenith angle, and relative azimuth angle. One can see that, irrespective of the spatial scale, CAR observations are sampled across a broad range of viewing and illumination conditions. A slight divergence occurs at observations with GIFOVs $>90 \mathrm{~m}$. Due to a limited flight ceiling of $\sim 4 \mathrm{~km}$, the lowest view zenith angle achieved across this particular range was $\sim 30^{\circ}$ (Fig. 9b). While this limited view angle range may somewhat affect the quality of the BRDF model inversions at moderate spatial resolutions (i.e., scale $=240 \mathrm{~m}$ ), a detailed characterization of the uncertainties (as described in Section 2.3) was performed to determine whether each retrieval was accessing enough information of the theoretical reflectance space to accurately retrieve the RTLSR model parameters. As a result, retrievals are supported by extensive quality assurance information to make sure that the output is appropriate for validation and inter-comparison purposes.

Fig. 8c illustrates the spatial distribution of the Quality Assurance (QA) Science Data Set (SDS) generated by the retrieval scheme. This layer provides basic QA for BRDF model inversion data, with green pixels denoting high-quality full inversion retrievals, red pixels denoting moderate quality magnitude inversion retrievals, and yellow pixels denoting gap-filled values (i.e., using the ancillary BRDF database and employing the linear-mixture assumption $-c f$., Section 4.1 ) for areas with insufficient $(<1)$ observations. Unless a sufficient number of observations ( $>7$ ) were available, water-contaminated areas (i.e., black pixels) were not processed. Notice that the spatial distribution of highquality (or full inversion) retrievals varies according to the scale of sampling. The $30 \mathrm{~m}$ BRDF fields were primarily centered on the CART site, but as the aircraft moved to higher altitudes (i.e., to acquire surface BRFs at GIFOVs $>45 \mathrm{~m}$ ), more observations were acquired northwest of the site. Despite this effect, a sufficient number of full inversion retrievals (totaling an area of $\sim 4.5 \mathrm{~km}^{2}$ ) were observed similarly in terms of spatial and angular sampling. Note that, since the gap-filled BRDF retrievals from CAR are spatially-invariant by nature (i.e., regardless of scale, the resulting mixture of BRDFs originate from the same source) these retrievals were only used to improve the spatial coverage. Accordingly, only full inversion retrievals were used to perform the multiscale comparisons and uncertainty analyses presented in the discussion (i.e., Section 4).

During the CLASIC experiment, the number of cloud-free acquisitions from the MODIS sensors onboard the Terra and Aqua satellites were impacted by changing weather conditions (e.g., rainfall events) (Bindlish et al., 2009; Heathman et al., 2009). Since the MODIS Collection 5 BRDF/ albedo algorithm assumes the surface reflectance anisotropy to remain stable for a period of 16 days, high-quality full inversion retrievals were obtained for less than $20 \%$ of the total $10 \mathrm{~km}^{2}$ study area. To address the extensive data gaps caused by persistent clouds, gap-free, qualityenhanced retrievals (Zhang, 2008) were used to reconstruct the surface reflectance anisotropy of the CART site during the CLASIC experiment. By applying temporal fitting techniques based on vegetation yearly development and spatial fitting techniques to the MODIS RTLSR BRDF model inversions - similar to the techniques previously applied to the MODIS albedo products (Moody et al., 2008) and the MODIS leaf area index (LAI) products (Gao et al., 2008) - this approach was able to compensate for missing data and provide an estimate of the surface reflectance anisotropy for situations under cloud-contaminated conditions. It is important to note, however, that despite the usefulness of this retrieval method in maximizing the influence of available observations, the resulting BRDF fields can only provide a close (but not exact) representation of the surface conditions during the CLASIC experiment. Thus it is difficult to determine, through this approach, whether rapidly changing surface conditions resulting from flooding and agricultural activities are being captured completely and accurately throughout this period. Nevertheless, a judicious use of available in-situ and ancillary datasets should provide sufficient constrains to address land cover/use changes resulting from events following Flight \#1928.

\section{Results and discussion}

The purpose of this section is to demonstrate results from the new BRDF retrieval scheme with inversion of data from the CLASIC experiment. We will also examine the uncertainties in BRDF retrievals resulting from utilization of land cover type-specific a priori knowledge in kernel-driven BRDF model inversions, and establish the accuracy, precision, and uncertainty of retrievals from the MODIS Collection 5 BRDF model parameters product (MDC43A1).

\subsection{A priori knowledge in kernel-driven BRDF model inversions}

We now examine the major assumptions underlying the use of land cover type-specific a priori knowledge in kernel-driven BRDF model inversions (Lewis, 1995). This was achieved by establishing the uncertainty of BRDF model reconstructions that seek to describe the surface anisotropy as either: (1) a linear-mixture of different land cover types; or (2) a single (or dominant) land cover type. The goal of this exercise is to provide additional constrains into the appropriate spatial length scales and degree of subpixel detail necessary to retrieve the BRDF of a target using land cover type-specific a priori knowledge.

Linear-mixture BRDF model reconstructions were obtained by combining the CLASIC land cover map (Fig. 4a), the RTLSR kernel coefficients of the CLASIC ancillary BRDF database (Table 1), and Eqs. (26) and (27). The dominant BRDF model reconstructions were obtained using the same equations and data sources as the linearmixture case; with the exception that only the RTLSR kernel weights of the dominant class (i.e., the land cover type with the largest proportional weight) was used. For all cases, the RMS of relative error (\%):

RMS of relative error $(\Lambda)=\sqrt{\frac{\sum_{i=1}^{n}\left(\frac{\rho\left(\theta_{s}^{i}, \theta_{v}^{i}, \Delta \phi^{i}, \Lambda\right)-R\left(\theta_{s}^{i}, \theta_{v}^{i}, \Delta \phi^{i}, \Lambda\right)}{\rho\left(\theta_{s}^{i}, \theta_{v}^{i}, \Delta \phi^{i}, \Lambda\right)}\right)^{2}}{n-3}}$ 

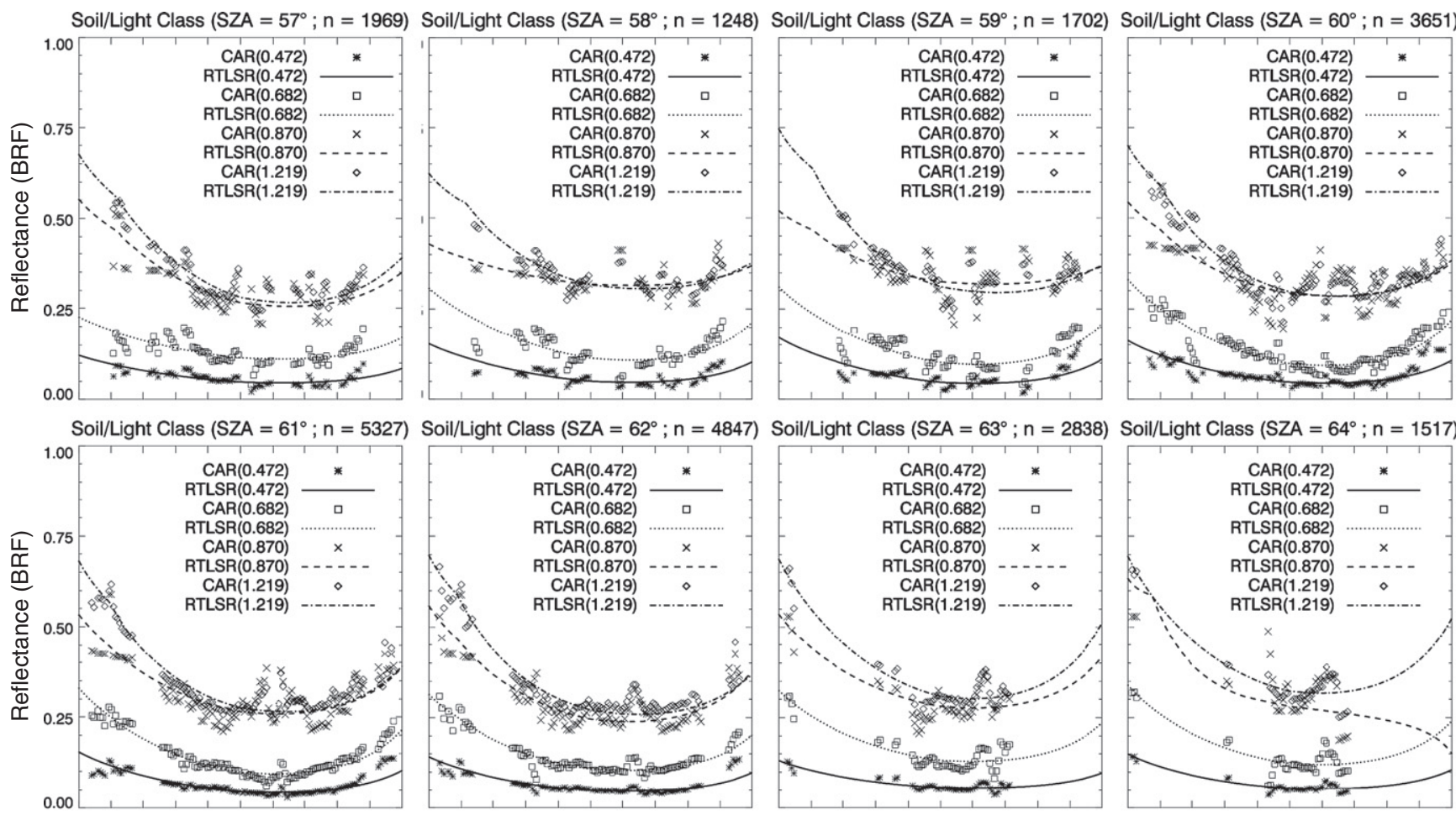

Soil/Light Class $\left(\mathrm{SZA}=65^{\circ} ; n=1644\right)$ Soil/Light Class (SZA $\left.=66^{\circ} ; n=2686\right)$
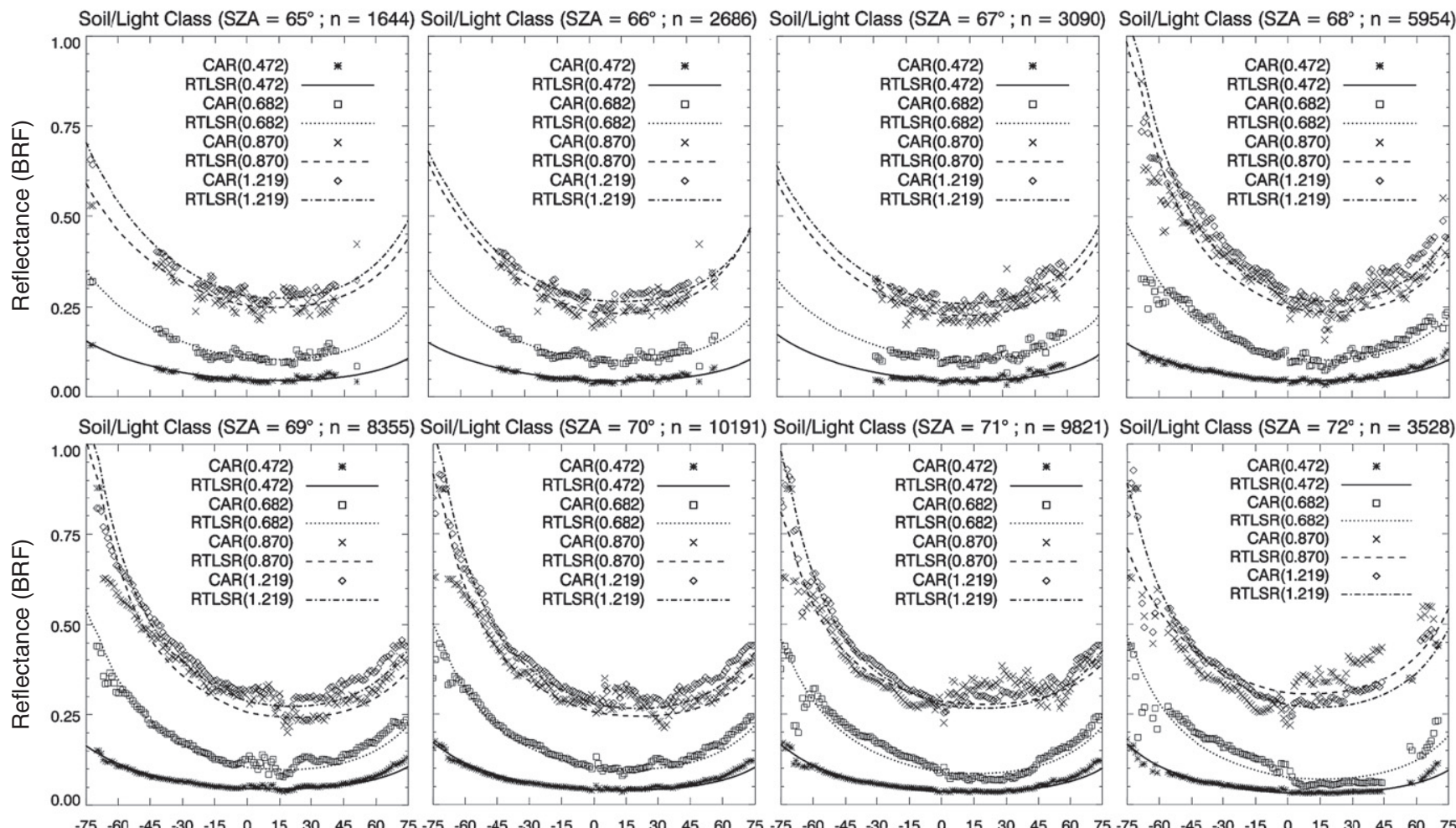

Principal Plane View Zenith Angle $\left({ }^{\circ}\right)$

Fig. 7. Angular distribution of the BRF in the principal plane collected over areas with light soils as observed during CLASIC Flight \#1928. Setup is the same as Fig. 6.

was obtained by simulating the BRF at the angular sampling of all observations over a given CAR grid cell; thus obtaining (model-fits) error estimates for various spectral bands and spatial scales. The assumptions were then tested in parallel by comparing the relative model-fits (RMS) errors from high-quality, full inversion, retrievals against the linear-mixture and dominant BRDF reconstructions. Since, the RMS of relative error (\%) establishes the deviation of the RTLSR model-fits from actual surface BRF measurements from CAR, these evaluations should result in uncertainty estimates that are of equal (or comparable) magnitude to those derived through direct means. Thus, if BRDF model reconstructions employing the CLASIC ancillary BRDF database as the primary source of a priori knowledge can truly characterize the anisotropic reflectance characteristics of a mixed agricultural landscape, then the cumulative distribution of differences 
Table 1

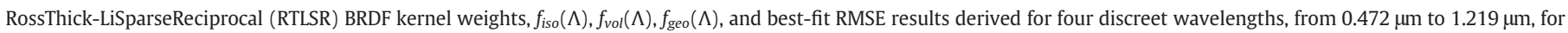
each of the representative land cover types identified across the CART site during the CLASIC experiment.

\begin{tabular}{|c|c|c|c|c|c|c|c|c|}
\hline \multirow[t]{2}{*}{ Surface type } & \multicolumn{4}{|c|}{ RTLSR BRDF $(0.472 \mu \mathrm{m})$} & \multicolumn{4}{|c|}{ RTLSR BRDF $(0.682 \mu \mathrm{m})$} \\
\hline & fiso $(\Lambda)$ & $f \operatorname{vol}(\Lambda)$ & fgeo $(\Lambda)$ & $\operatorname{RMSE}(\Lambda)$ & fiso $(\Lambda)$ & $\operatorname{fvol}(\Lambda)$ & $\operatorname{fgeo}(\Lambda)$ & $\operatorname{RMSE}(\Lambda)$ \\
\hline Grass/pasture & 0.0303 & 0.0553 & 0.0022 & 0.0108 & 0.0579 & 0.0941 & 0.0058 & 0.0213 \\
\hline Trees/shrubs & 0.0308 & 0.0433 & 0.0030 & 0.0112 & 0.0610 & 0.0649 & 0.0065 & 0.0224 \\
\hline Corn/milo & 0.0335 & 0.0692 & 0.0005 & 0.0138 & 0.0666 & 0.1074 & 0.0026 & 0.0265 \\
\hline Wheat/stubble & 0.0437 & 0.0419 & 0.0043 & 0.0105 & 0.0916 & 0.0672 & 0.0093 & 0.0240 \\
\hline Bare soil/short grass & 0.0500 & 0.0490 & 0.0019 & 0.0124 & 0.1021 & 0.0723 & 0.0031 & 0.0260 \\
\hline Bare soil dark & 0.0390 & 0.0470 & 0.0014 & 0.0100 & 0.0922 & 0.0839 & 0.0045 & 0.0234 \\
\hline Bare soil medium & 0.0458 & 0.0544 & 0.0032 & 0.0089 & 0.1050 & 0.1046 & 0.0093 & 0.0191 \\
\hline Bare soil light & 0.0497 & 0.0596 & 0.0027 & 0.0083 & 0.1282 & 0.1253 & 0.0150 & 0.0222 \\
\hline \multirow[t]{2}{*}{ Surface type } & \multicolumn{4}{|c|}{ RTLSR BRDF $(0.870 \mu \mathrm{m})$} & \multicolumn{4}{|c|}{ RTLSR BRDF $(1.219 \mu \mathrm{m})$} \\
\hline & fiso $(\Lambda)$ & $\operatorname{fvol}(\Lambda)$ & $\operatorname{fgeo}(\Lambda)$ & $\operatorname{RMSE}(\Lambda)$ & fiso $(\Lambda)$ & $f \operatorname{vol}(\Lambda)$ & $\operatorname{fgeo}(\Lambda)$ & $\operatorname{RMSE}(\Lambda)$ \\
\hline Grass/pasture & 0.3777 & 0.1108 & 0.0023 & 0.0442 & 0.3357 & 0.2483 & 0.0181 & 0.0378 \\
\hline Trees/shrubs & 0.3444 & 0.1497 & 0.0082 & 0.0479 & 0.3300 & 0.2667 & 0.0268 & 0.0473 \\
\hline Corn/milo & 0.3712 & 0.1315 & 0.0051 & 0.0535 & 0.3306 & 0.2754 & 0.0136 & 0.0431 \\
\hline Wheat/stubble & 0.3291 & 0.2026 & 0.0154 & 0.0648 & 0.3430 & 0.2559 & 0.0340 & 0.0425 \\
\hline Bare soil/short grass & 0.3299 & 0.0890 & 0.0207 & 0.0486 & 0.3663 & 0.1787 & 0.0424 & 0.0419 \\
\hline Bare soil dark & 0.3201 & 0.1860 & 0.0117 & 0.0504 & 0.3194 & 0.2437 & 0.0157 & 0.0399 \\
\hline Bare soil medium & 0.2911 & 0.1889 & 0.0184 & 0.0394 & 0.3284 & 0.2285 & 0.0346 & 0.0320 \\
\hline Bare soil light & 0.2972 & 0.1612 & 0.0237 & 0.0387 & 0.3435 & 0.2217 & 0.0369 & 0.0342 \\
\hline
\end{tabular}
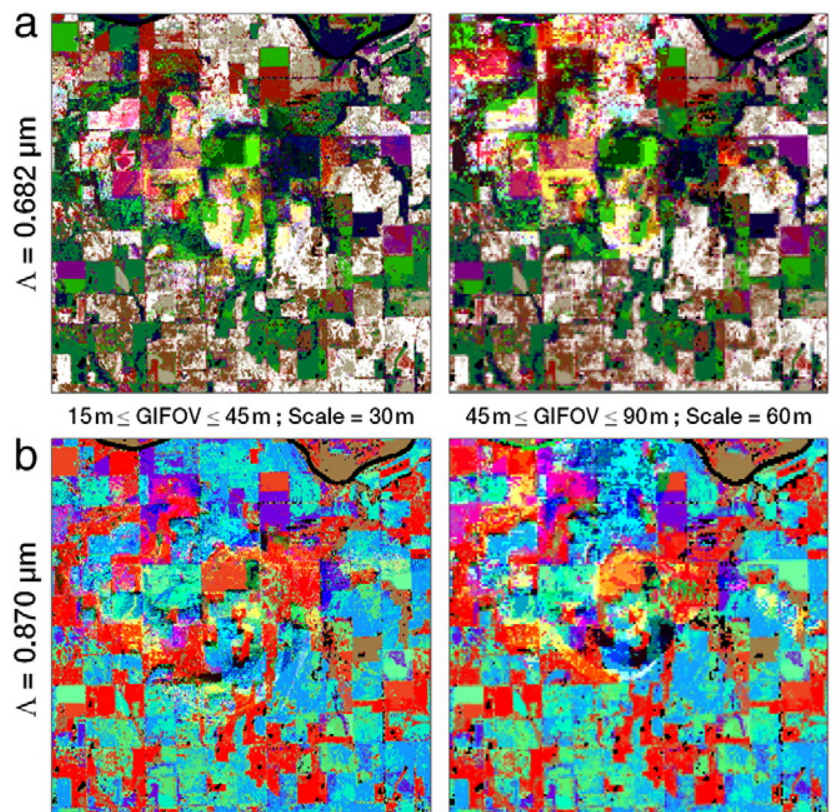

$45 \mathrm{~m} \leq$ GIFOV $\leq 90 \mathrm{~m} ;$ Scale $=60 \mathrm{~m}$
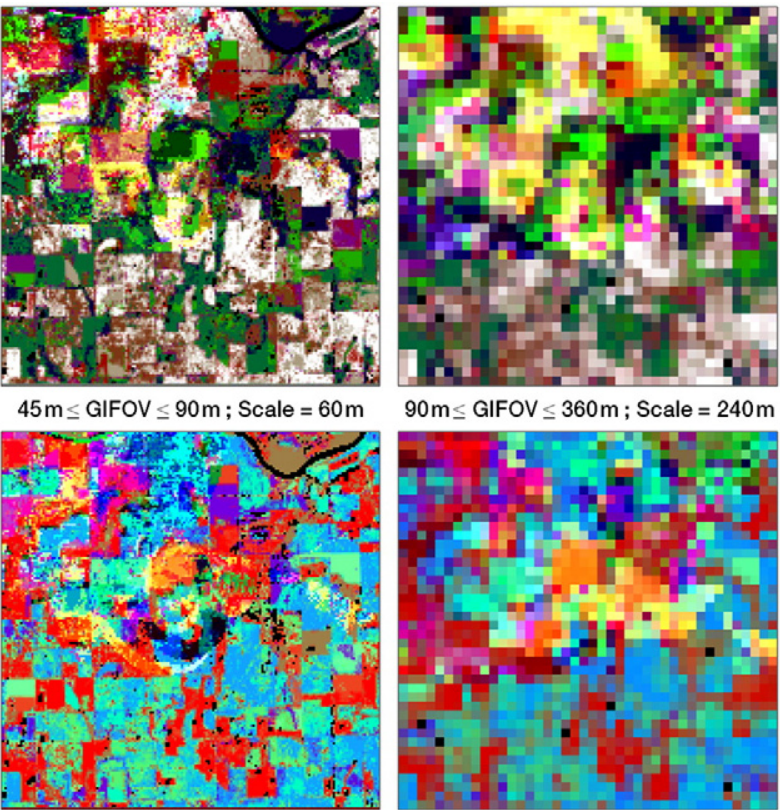

$90 \mathrm{~m} \leq$ GIFOV $\leq 360 \mathrm{~m} ;$ Scale $=240 \mathrm{~m}$

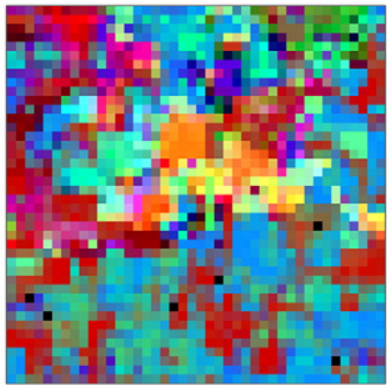

Red $=f_{\text {iso }}(\Lambda) ;$ Green $=f_{\text {vol }}(\Lambda) ;$ Blue $=f_{\text {geo }}(\Lambda)$

C

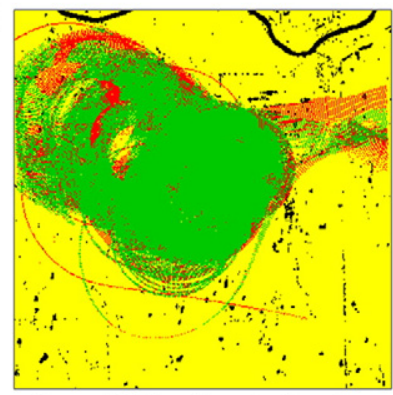

$15 \mathrm{~m} \leq$ GIFOV $\leq 45 \mathrm{~m} ;$ Scale $=30 \mathrm{~m}$

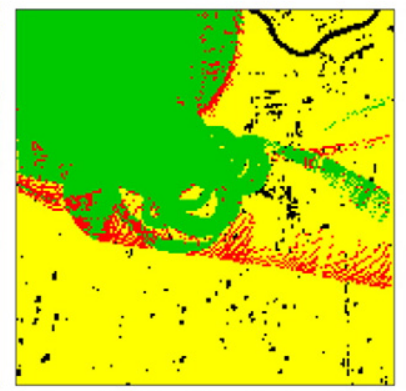

$45 \mathrm{~m} \leq$ GIFOV $\leq 90 \mathrm{~m} ;$ Scale $=60 \mathrm{~m}$

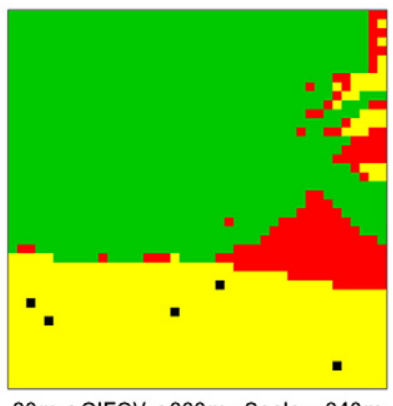

$90 \mathrm{~m} \leq$ GIFOV $\leq 360 \mathrm{~m} ;$ Scale $=240 \mathrm{~m}$

Full Inversion

Mag. Inversion

NumObs $<7$

Values
Not Processed

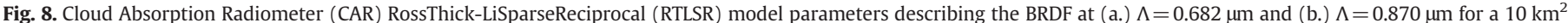

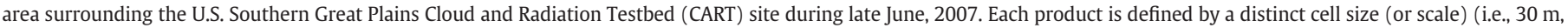

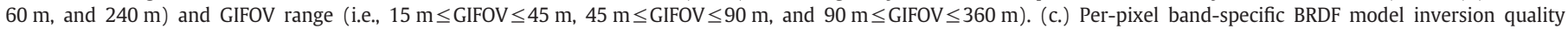
equivalent to the MODIS BRDF/Albedo quality Level 3 product (MCD43A2). 

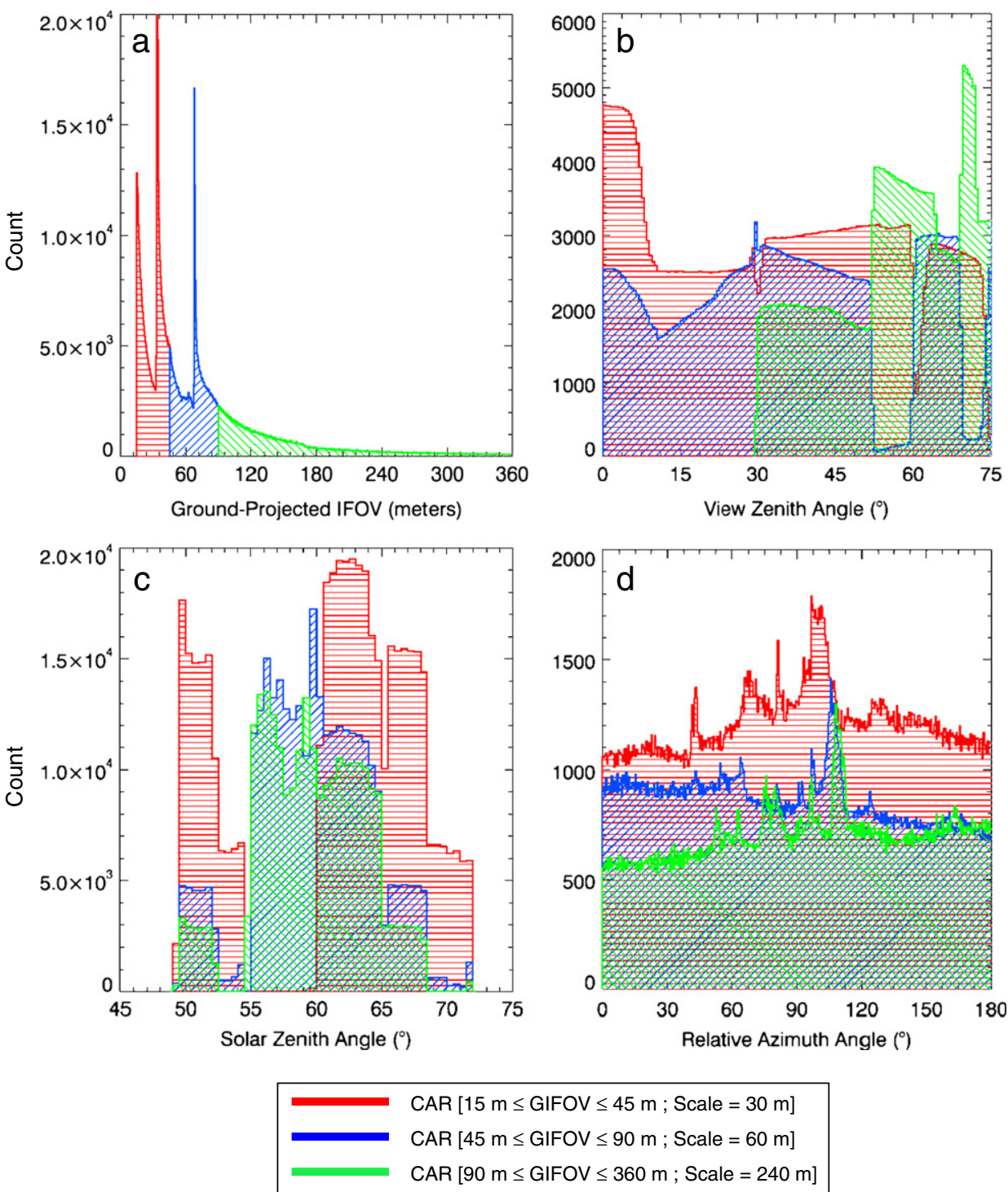

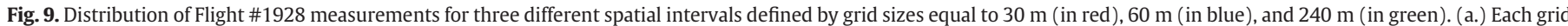

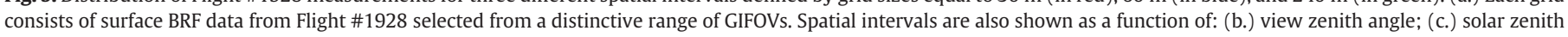
angle; and (d.) relative azimuth angle.

in RMS of relative error (i.e., RMS\% Archetypal - RMS\% Full Inversion) should follow a normal pattern with a limit equal or close to zero. Note that, based on the scaling principles of linear BRDF modeling theory, this should apply regardless of the scale at which the assumptions are being examined.

Results in Fig. 10 confirm that the RMS of relative error for the archetypal BRDF model reconstructions are moderately higher than the full-inversion results. The uncertainties are also consistently larger in the shorter wavelengths $(\Lambda \leq 0.682 \mu \mathrm{m})$ and smaller at the longer wavelengths $(\Lambda \geq 0.870 \mu \mathrm{m})$. Improvements in the range of 0.5\%-6.5\% were also documented when replacing the dominant BRDF model reconstructions with the linear-mixture case. Finally, with the exception of the blue CAR channel $(\Lambda=0.472 \mu \mathrm{m})$, retrievals at coarser spatial resolutions (i.e., $>90 \mathrm{~m}$ ) were consistently of higher quality than those retrieved at finer spatial resolutions (i.e., $<45 \mathrm{~m}$ ). Thus, while the utilization of land cover type-specific a priori knowledge obtained at fine spatial scales is usually assumed to capture the angular variability of a spatially heterogeneous environment, these results suggest that the assumption of linearity in kernel- driven BRDF models may in fact be most appropriate at "landscapelevel" scales (i.e., >90 m).

\subsection{Accuracy, precision, and uncertainty assessment}

Due to constraints of instrumentation, platform, and the logisticallychallenging nature of airborne data collection and processing, most airborne multiangle experiments have been unable to acquire spatiallydistributed BRDF data at landscape-level scales $>90 \mathrm{~m}$ (Walthall et al., 2000). To get around this problem, previous studies have stipulated that in-situ measurements acquired at scales larger than the intrinsic length scale of the surface should represent the BRDF patterns observed at larger spatial scales (Brown de Colstoun et al., 1996; Leroy et al., 1997; Qin \& Gerstl, 2000). In general, a GIFOV $\geq 15 \mathrm{~m}$ has been routinely used to provide an adequate sample of the BRDF at subpixel scales (Pelgrum et al., 2000; Chopping et al., 2002). Thus, up to now, the only alternative has been to simulate a larger GIFOV by convolving fine-resolution estimates with the point spread function (PSF) of a moderate resolution satellite sensor. For instance, the AirMISR instrument with an effective 

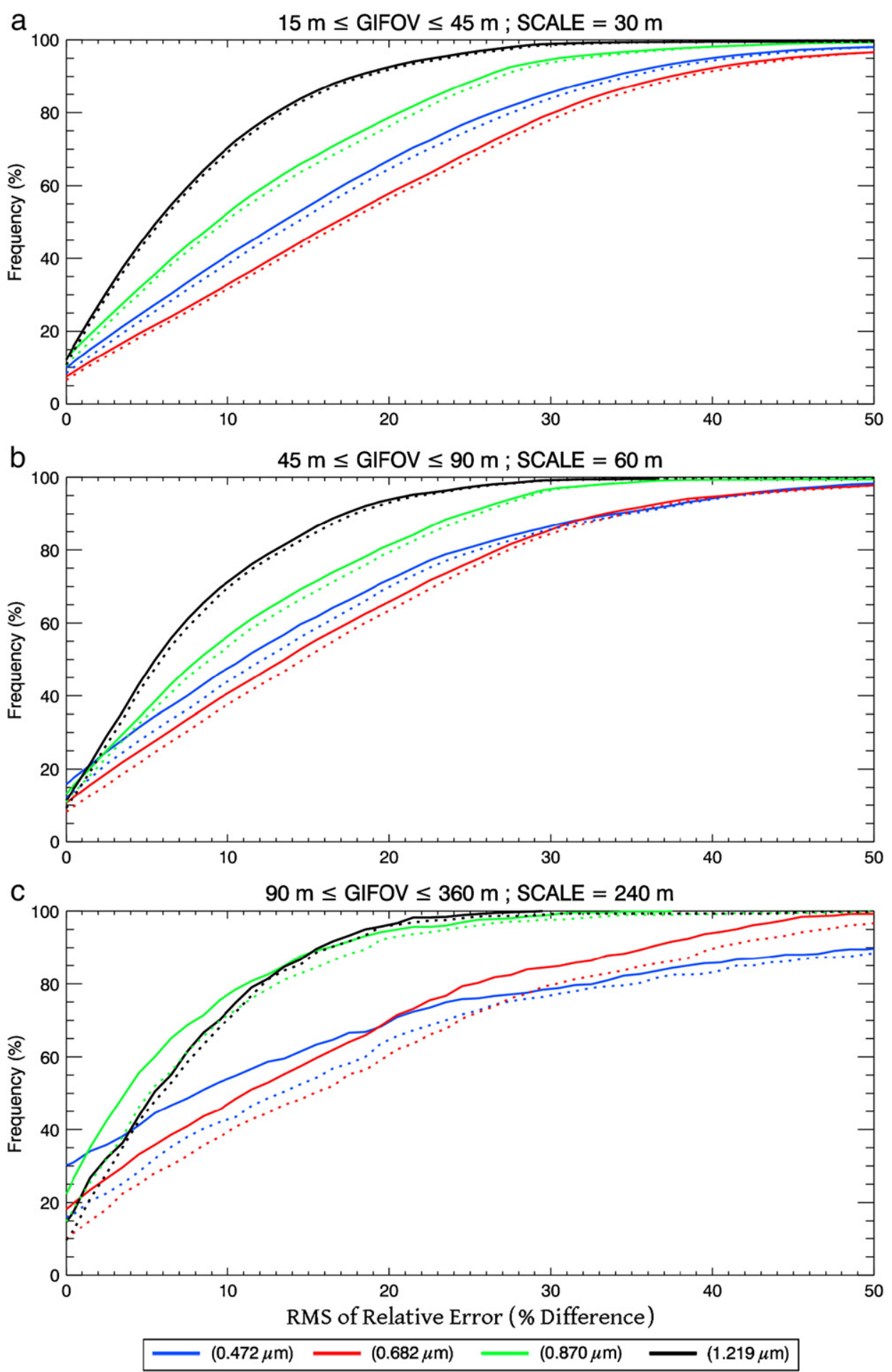

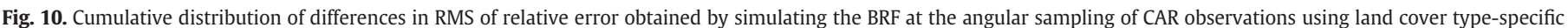

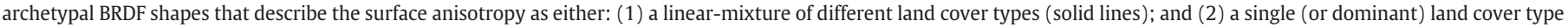
(dotted lines). Results are available for three grid cell sizes equal to $30 \mathrm{~m}$ (a.), $60 \mathrm{~m}$ (b.), and $240 \mathrm{~m}$ (c.); and for four discreet wavelengths from $0.472 \mu \mathrm{m}$ to $1.219 \mu \mathrm{m}$.

pixel size of $27.5 \mathrm{~m}$ at nadir, which grows at steeper angles (Diner et al., 1998a), is upscaled to match MISR's effective spatial resolution of $275 \mathrm{~m}$ (Gobron et al., 2002; Pinty et al., 2002). The same spatial scaling principle is applied to the MODIS Airborne Simulator (MAS) (King et al., 1996), which has an effective pixel size of $50 \mathrm{~m}$, and is upscaled to MODIS spatial resolutions $>250 \mathrm{~m}$. The assumption, then, is that the aggregated BRDF datasets should scale linearly in a spatial sense
(Roujean et al., 1992; Lewis, 1995). However, because the scale for shadowing and clumping effects depends on spatial resolution, such upscaled results can lead to different spatial and structural patterns (d'Entremont et al., 1999; Walthall et al., 2000). As a result, high spatial resolution BRDF retrievals that are convolved to a larger GIFOV may still be conditioned by the BRDF patterns observed at plot-level scales. To demonstrate this effect, Fig. 11 illustrates the spatial and angular 
CAR BRF $[15 \mathrm{~m} \leq \mathrm{GIFOV} \leq 45 \mathrm{~m} ;$ Scale $=30 \mathrm{~m}]$
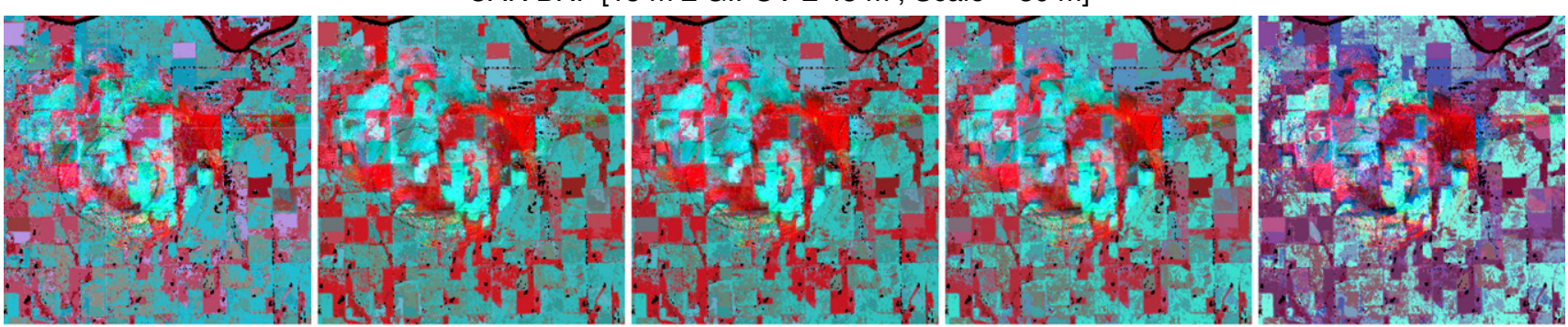

CAR BRF $[45 \mathrm{~m} \leq \mathrm{GIFOV} \leq 90 \mathrm{~m} ;$ Scale $=60 \mathrm{~m}]$
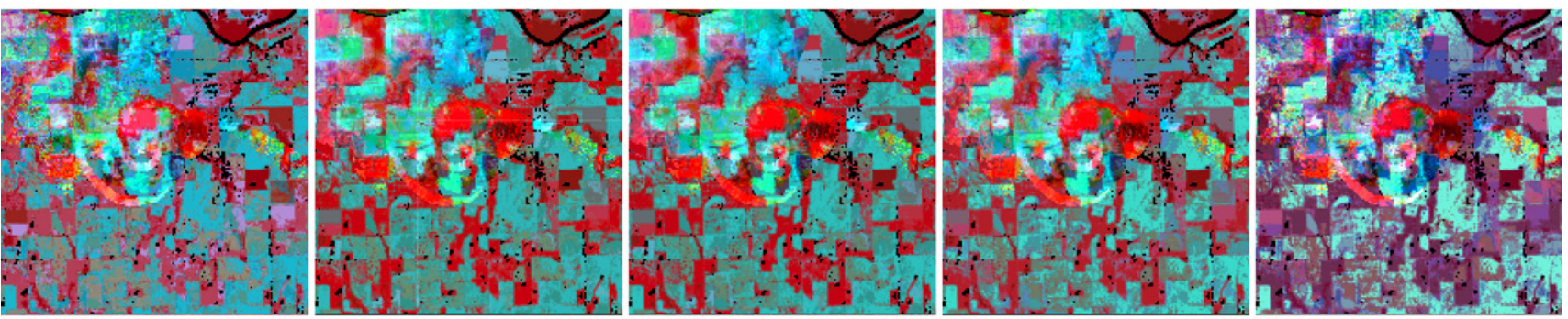

CAR BRF $[90 \mathrm{~m} \leq$ GIFOV $\leq 360 \mathrm{~m} ;$ Scale $=240 \mathrm{~m}]$
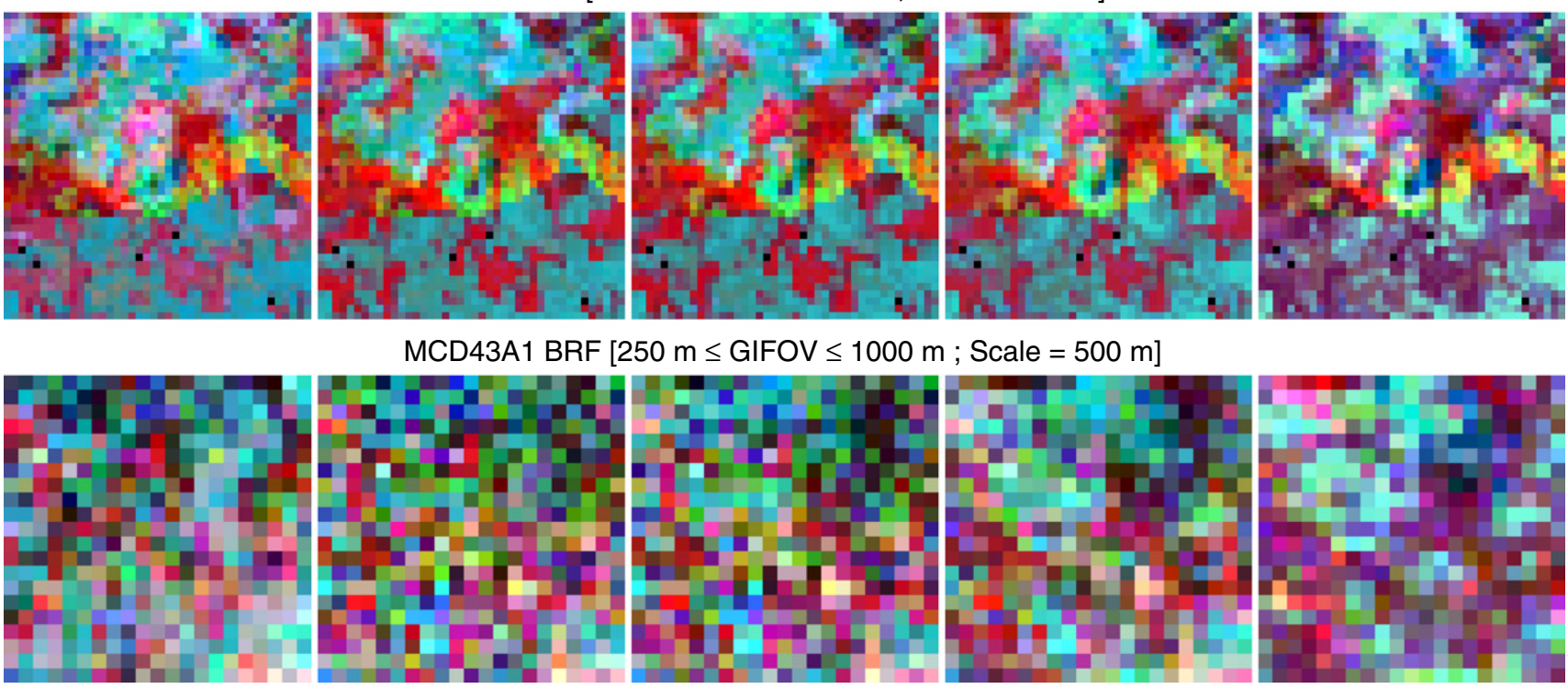

$$
\theta_{\mathrm{v}}=-60.0^{\circ}
$$

$$
\theta_{\mathrm{v}}=-30.0^{\circ}
$$

$$
\theta_{\mathrm{v}}=0.0^{\circ}
$$

$\theta_{\mathrm{V}}=30.0^{\circ}$

$\theta_{\mathrm{v}}=60.0^{\circ}$

Red $=\operatorname{BRF}(0.870 \mu \mathrm{m}) ;$ Green $=\operatorname{BRF}(0.682 \mu \mathrm{m}) ; \operatorname{Blue}=\operatorname{BRF}(0.472 \mu \mathrm{m})$

Fig. 11. Principal plane surface BRF fields derived from CAR Flight \#1928 and MODIS Collection 5 (MDC43A1) RossThick-LiSparseReciprocal (RTLSR) BRDF model parameters over the CART site.

characteristics of CAR and MODIS Collection 5 BRDF model inversions (MCD43A1). Each false-color composite describes the spectral BRF response at $0.870 \mu \mathrm{m}$ (Red), $0.682 \mu \mathrm{m}$ (Green), and $0.472 \mu \mathrm{m}$ (Blue), for five different view zenith angle intervals measured across the principal plane (i.e., $\Delta \phi=0^{\circ}$ ) and using a $\mathrm{SZA}=60^{\circ}$. Negative VZA values represent the backscattering while positive values represent the forward scattering. In the back scattering direction, pastures and crop fields show a strong directional response in the NIR (as seen in brightreds and pink colors); while bare soils show a lower directional response (as seen by shades of pale-blue and cyan). Conversely, increased shadowing in the forward scattering results in a lower response in the red and NIR (as seen in dark purple and magenta tones), which then increases the overall contrast of bare soils (as seen in dark and bright shades of cyan). The histograms in Fig. 12 illustrate the distribution for each of the view-angle geometries examined in Fig. 11, using four discreet wavelengths from $0.472 \mu \mathrm{m}(0.465 \mu \mathrm{m}$ for MODIS) to $1.219 \mu \mathrm{m}$ (1.241 $\mu \mathrm{m}$ for MODIS). Results show a good degree of correspondence between CAR and MODIS BRFs at view angles closer to nadir (i.e., $-30^{\circ} \leq \mathrm{VZA} \leq+30^{\circ}$ ), with improved results for wavelengths $\leq 0.682 \mu \mathrm{m}$. However, at high view zenith angles, the spread of the distribution in the BRF tends to be narrower at spatial scales $\leq 60 \mathrm{~m}$ and broader at scales $\geq 240 \mathrm{~m}$. At landscape-level scales, this results in higher BRF values across the backscattering and lower BRF values across the forward scattering directions. Conversely, at scales $\leq 60 \mathrm{~m}$, vegetated areas exhibit a strong directional response in the forward scattering, and (with the exception of the $1.219 \mu \mathrm{m}$ channel) appear darker in the backscattering. These scaling effects may result from distinct spatial and structural BRDF patterns, including: (1) subpixel 

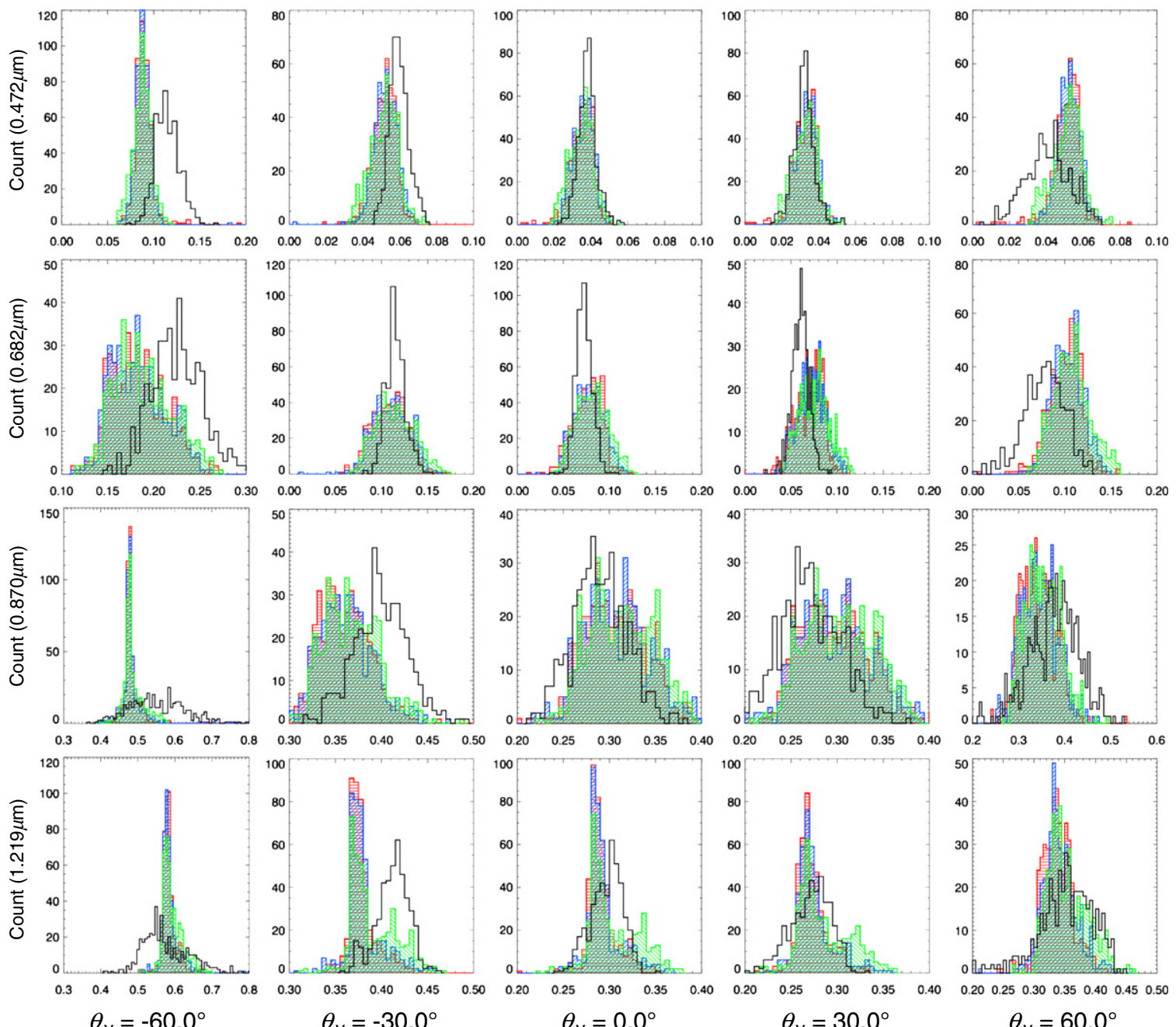

$$
\begin{array}{|l}
\theta_{\mathrm{v}}=-30.0^{\circ} \quad \theta_{\mathrm{v}}=0.0^{\circ} \quad \theta_{\mathrm{v}}=30.0^{\circ} \\
\text { CAR }[15 \mathrm{~m} \leq \mathrm{GIFOV} \leq 45 \mathrm{~m} ; \text { Scale }=30 \mathrm{~m}] \\
\text { CAR }[45 \mathrm{~m} \leq \mathrm{GIFOV} \leq 90 \mathrm{~m} ; \text { Scale }=60 \mathrm{~m}] \\
\text { CAR }[90 \mathrm{~m} \leq \mathrm{GIFOV} \leq 360 \mathrm{~m} ; \text { Scale }=240 \mathrm{~m}] \\
\text { MCD43A1 }[250 \mathrm{~m} \leq \mathrm{GIFOV} \leq 1000 \mathrm{~m} ; \text { Scale }=500 \mathrm{~m}]
\end{array}
$$

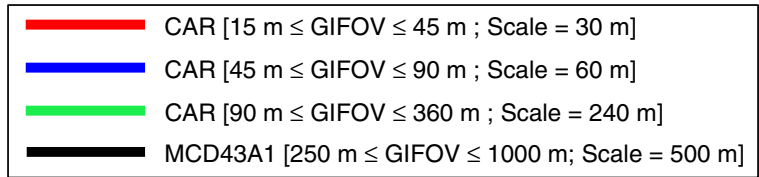$$
\theta_{\mathrm{v}}=60.0^{\circ}
$$

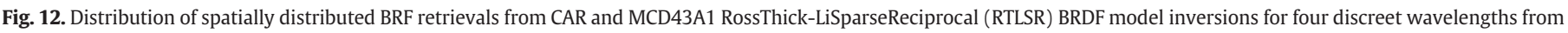
$0.472 \mu \mathrm{m}$ (top) to $1.219 \mu \mathrm{m}$ (bottom).

differences in the BRDF (e.g., row and close-grown crops or mosaics of crops with natural vegetation) observed at spatial resolutions $>90 \mathrm{~m}$, which decreases the overall slope of the BRDF shape at moderate spatial resolutions; (2) the influence of specular reflection and transmission of light at spatial resolutions $\leq 60 \mathrm{~m}$; and (3) the fundamental scales of shadowing for foliage and canopy components manifested at spatial resolutions $>90 \mathrm{~m}$.

In order to quantify the uncertainties that arise when sub-pixel differences in the BRDF are aggregated to a moderate resolution satellite pixel, the quality of MODIS RTLSR surface BRF retrievals was evaluated across spatial scales. Results in Table 2 show that the MODIS retrievals are more consistent with CAR-derived BRFs at moderate spatial resolutions (i.e., scale $=240 \mathrm{~m}$ ). The quality of these direct "moderate pixel-to-moderate pixel" comparisons resulted in APU units that were $1.15 \%$ more accurate, $3.59 \%$ more precise, and 0.005 less uncertain ( $c f$., Table 2 for APU metrics). While the finer scale CAR BRFs (i.e., scale $=30 \mathrm{~m}$ ) were, at times, as consistent as the $240 \mathrm{~m}$ BRDF fields, the intermediate results (i.e., scale $=60 \mathrm{~m}$ ) were not as reliable. The most significant improvement resulted from the ability of moderate resolution retrievals from CAR to capture the range of mixed BRDF patterns as observed by a MODIS $500 \mathrm{~m}$ grid cell. This resulted in more precise (and thus, less uncertain) estimates.

\section{Conclusions}

In previous aircraft campaigns using a variety of multiangular sensors, e.g., FIFE (Sellers et al., 1988, 1992), OTTER (Waring \& Peterson, 1994), HAPEX-Sahel (Goutorbe et al., 1994), BOREAS (Russell et al., 1997), PROVE (Privette et al., 2000), and SAFARI 2000 (Swap et al., 2002; Privette et al., 2004) it was common to acquire multiangle surface bidirectional reflectance factor (BRF) measurements and then compare them directly against coincident ground and/or satellite data to obtain information on both the structure and functioning of terrestrial ecosystems. As we note, these "point-topixel" comparisons are influenced by very distinct spatial and structural patterns, including: (1) subpixel differences in the BRDF 
Table 2

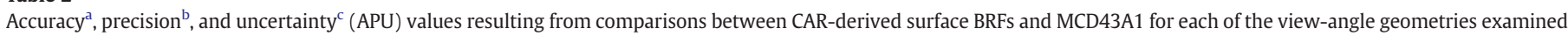
in Figs. 9 and 10. For each case, the values in bold denote the best estimate across spatial scales.

\begin{tabular}{|c|c|c|c|c|c|c|c|c|c|c|}
\hline \multirow[t]{2}{*}{ Band } & \multirow[t]{2}{*}{ VZA } & \multicolumn{3}{|c|}{$\begin{array}{l}\text { CAR }[15 \mathrm{~m} \leq \text { GIFOV } \leq 45 \mathrm{~m} \text {; scale }=30 \mathrm{~m}] \\
\text { vs. MCD43A1 }\end{array}$} & \multicolumn{3}{|c|}{$\begin{array}{l}\text { CAR }[45 \mathrm{~m} \leq \text { GIFOV } \leq 90 \mathrm{~m} \text {; scale }=60 \mathrm{~m}] \\
\text { vs. MCD } 43 \mathrm{~A} 1\end{array}$} & \multicolumn{3}{|c|}{$\begin{array}{l}\text { CAR }[90 \mathrm{~m} \leq \mathrm{GIFOV} \leq 360 \mathrm{~m} ; \text { scale }=240 \mathrm{~m}] \\
\text { vs. } \mathrm{MCD} 43 \mathrm{~A} 1\end{array}$} \\
\hline & & Accuracy & Precision & Uncertainty & Accuracy & Precision & Uncertainty & Accuracy & Precision & Uncertainty \\
\hline $0.472 \mu \mathrm{m}$ & $-60^{\circ}$ & $-32.70 \%$ & $20.99 \%$ & 0.0313 & $-30.20 \%$ & $20.49 \%$ & 0.0380 & $-29.63 \%$ & $19.83 \%$ & 0.0311 \\
\hline $0.472 \mu \mathrm{m}$ & $-30^{\circ}$ & $-17.71 \%$ & $20.55 \%$ & 0.1150 & $-17.47 \%$ & $21.76 \%$ & 0.0120 & $-16.74 \%$ & $19.85 \%$ & 0.1120 \\
\hline $0.472 \mu \mathrm{m}$ & $0^{\circ}$ & $-11.18 \%$ & $39.02 \%$ & 0.0097 & $-5.96 \%$ & $36.40 \%$ & 0.0172 & $-13.38 \%$ & $26.18 \%$ & 0.0082 \\
\hline $0.472 \mu \mathrm{m}$ & $30^{\circ}$ & $-7.95 \%$ & $28.49 \%$ & 0.0107 & $4.41 \%$ & $28.19 \%$ & 0.0217 & $-2.06 \%$ & $28.02 \%$ & 0.0081 \\
\hline $0.472 \mu \mathrm{m}$ & $60^{\circ}$ & $17.68 \%$ & $28.11 \%$ & 0.0194 & $22.91 \%$ & $29.80 \%$ & 0.0314 & $18.92 \%$ & $27.94 \%$ & 0.0178 \\
\hline $0.682 \mu \mathrm{m}$ & $-60^{\circ}$ & $-25.40 \%$ & $24.93 \%$ & 0.0580 & $-24.68 \%$ & $24.92 \%$ & 0.0591 & $-22.12 \%$ & $23.25 \%$ & 0.0526 \\
\hline $0.682 \mu \mathrm{m}$ & $-30^{\circ}$ & $-9.14 \%$ & $22.58 \%$ & 0.0223 & $-9.48 \%$ & $22.40 \%$ & 0.0224 & $-3.91 \%$ & $20.57 \%$ & 0.0219 \\
\hline $0.682 \mu \mathrm{m}$ & $0^{\circ}$ & $1.18 \%$ & $34.31 \%$ & 0.0184 & $3.96 \%$ & $30.78 \%$ & 0.0231 & $6.33 \%$ & $23.29 \%$ & 0.0205 \\
\hline $0.682 \mu \mathrm{m}$ & $30^{\circ}$ & $16.66 \%$ & $25.52 \%$ & 0.0209 & $15.86 \%$ & $27.63 \%$ & 0.0280 & $16.13 \%$ & $23.47 \%$ & 0.0241 \\
\hline $0.682 \mu \mathrm{m}$ & $60^{\circ}$ & $17.94 \%$ & $47.66 \%$ & 0.0372 & $26.97 \%$ & $42.11 \%$ & 0.0450 & $25.47 \%$ & $26.51 \%$ & 0.0426 \\
\hline $0.870 \mu \mathrm{m}$ & $-60^{\circ}$ & $-33.51 \%$ & $12.10 \%$ & 0.1717 & $-33.62 \%$ & $12.13 \%$ & 0.1697 & $-32.68 \%$ & $13.02 \%$ & 0.1673 \\
\hline $0.870 \mu \mathrm{m}$ & $-30^{\circ}$ & $-11.50 \%$ & $11.61 \%$ & 0.0567 & $-11.75 \%$ & $12.86 \%$ & 0.0582 & $-9.46 \%$ & $12.30 \%$ & 0.0541 \\
\hline $0.870 \mu \mathrm{m}$ & $0^{\circ}$ & $4.26 \%$ & $14.34 \%$ & 0.0477 & $2.92 \%$ & $24.84 \%$ & 0.0536 & $6.60 \%$ & $14.55 \%$ & 0.0530 \\
\hline $0.870 \mu \mathrm{m}$ & $30^{\circ}$ & $6.90 \%$ & $16.80 \%$ & 0.0554 & $11.40 \%$ & $14.48 \%$ & 0.0626 & $9.65 \%$ & $16.11 \%$ & 0.0611 \\
\hline $0.870 \mu \mathrm{m}$ & $60^{\circ}$ & $11.63 \%$ & $21.79 \%$ & 0.0748 & $11.51 \%$ & $21.47 \%$ & 0.0831 & $7.72 \%$ & $19.52 \%$ & 0.0705 \\
\hline $1.219 \mu \mathrm{m}$ & $-60^{\circ}$ & $-17.70 \%$ & $8.58 \%$ & 0.1141 & $-17.36 \%$ & $8.96 \%$ & 0.1133 & $-16.31 \%$ & $8.86 \%$ & 0.1080 \\
\hline $1.219 \mu \mathrm{m}$ & $-30^{\circ}$ & $-9.12 \%$ & $6.76 \%$ & 0.0423 & $-8.90 \%$ & $8.19 \%$ & 0.0434 & $-6.13 \%$ & $8.86 \%$ & 0.0403 \\
\hline $1.219 \mu \mathrm{m}$ & $0^{\circ}$ & $-2.51 \%$ & $8.35 \%$ & 0.0252 & $-4.76 \%$ & $43.59 \%$ & 0.0346 & $1.28 \%$ & $11.16 \%$ & 0.0352 \\
\hline $1.219 \mu \mathrm{m}$ & $30^{\circ}$ & $4.08 \%$ & $13.09 \%$ & 0.0415 & $7.78 \%$ & $15.52 \%$ & 0.0412 & $0.13 \%$ & $10.66 \%$ & 0.0289 \\
\hline $1.219 \mu \mathrm{m}$ & $60^{\circ}$ & $4.68 \%$ & $16.31 \%$ & 0.0605 & $0.53 \%$ & $17.07 \%$ & 0.0655 & $0.25 \%$ & $17.03 \%$ & 0.0551 \\
\hline
\end{tabular}

a Accuracy $=$ arithmetic mean $($ CAR - MODIS $) \times$ arithmetic mean $(\text { CAR })^{-1} \times 100 \%$,

b Precision $=$ standard deviation $($ CAR - MODIS $) \times$ arithmetic mean $(\text { CAR })^{-1} \times 100 \%$

c Uncertainty: RMS of absolute error $=\sqrt{\text { arithmeticmean }(C A R-M O D I S)^{2}}$.

observed at spatial resolutions $>90 \mathrm{~m}$; (2) the influence of specular reflection and transmission of light at spatial resolutions $<90 \mathrm{~m}$; and (3) the fundamental scales of shadowing for foliage and canopy components manifested at spatial resolutions $>90 \mathrm{~m}$. These scaling mechanisms, as well as other measurement uncertainties arising from geospatial aggregation of subpixel vegetation structural characteristics, can have potential impacts on the utility of multiangle data and products to characterize the ecological and biophysical state of complex ecosystems. Perhaps the biggest problem thus far has been the lack of adequate in-situ measurements and validation techniques for acquiring spatially-distributed surface BRDF data at the relevant spatial scales at which global land products are commonly utilized. While airborne measurements are commonly used to provide an intermediate scale between plot-level $(<15 \mathrm{~m})$ and landscape-level ( $>90 \mathrm{~m}$ ) measurements, the results from this work confirm that, as a result of the inherent lack of mixed-pixel sampling (i.e., both in spatial and angular sense), such approaches are not always appropriate for multiangle remote sensing studies.

With its unique design (i.e., a $190^{\circ}$ swath, $1^{\circ}$ IFOV, oversampling every $0.5^{\circ}$ along the vertical plane), unparalleled instrument accuracy $(\leq 5 \%)$, and flight capabilities (i.e., multiple circular patterns achieved at different heights above ground level under clear-sky conditions), NASA's Cloud Absorption Radiometer (CAR) is used to generate spatially-distributed BRDF products at different spatial scales. To demonstrate this capability, a new retrieval scheme was developed and applied to a single flight dataset containing $~ 1.6$ million individual surface BRFs obtained at view zenith angles from nadir to $75^{\circ}$ off-nadir, and at spatial resolutions ranging from $3 \mathrm{~m}$ to $500 \mathrm{~m}$. Results over a $10 \mathrm{~km}^{2}$ area centered on the well-instrumented CART site were then used to determine whether the ability of kerneldriven BRDF models to detect measures of canopy physiognomy and structure (e.g., through different manifestations of the surface reflectance anisotropy over the angular range) is independent of the spatial resolution of acquisition. Assessments between BRDF retrievals acquired from CAR at different spatial scales, and between CAR and MODIS (500 m) retrievals, confirm that while BRDF patterns observed at fine spatial resolutions (i.e., $\sim 15 \mathrm{~m}$ ) are usually assumed to be large enough to capture the intrinsic length scale of the surface, the utilization of land cover type-specific a priori knowledge, and the spatial scaling assumptions underlying semi-empirical kernel-driven BRDF models (Roujean et al., 1992; Lewis, 1995), may in fact be limited to considerably larger scales. These results are reminiscent of the findings in Widlowski et al. (2005) which, through physically based RT model simulations of surface BRFs acquired by an ideal sensor over coniferous forest representations at multiple spatial resolutions, predicted that hectare level $(\sim 100 \mathrm{~m})$ was approximately the optimal scale for BRDF retrieval. The results from this study offer new empirical evidence that only by acquiring BRDF retrievals at "landscape-level" scales (i.e., $>90 \mathrm{~m}$ ) can a resolution limit be reached whereby the resulting anisotropic reflectance characteristics of the surface are still representative of the structural response of complex ecosystems at the scale of moderate resolution satellite sensors. Nonetheless, further research is needed (particularly over landscapes with two-layer mixtures of woody overstory and herbaceous understory) to establish more definitive limits on the accuracy of these scaling assumptions. This would allow us to determine what kind of variability in the BRDF is important at what kind of scales.

With the advent of a new generation of multi-sensor data and products obtained through fusion of high-spatial resolution (e.g., Landsat TM/ETM+) and high-temporal resolution satellite datasets (e.g., MODIS and in the future VIIRS) (Gao et al., 2006; Roy et al., 2008), recent efforts have explored the "MODISization" of nadirlooking satellite sensors to obtain high-resolution (30 m) MODISdriven surface biophysical products at shorter temporal scales (i.e., from weeks to days). Earlier schemes have taken advantage of the temporal efficiency of MODIS (500 m) BRDF retrievals to (among several things) extrapolate the peak-growing season estimates of LAI and/or derive spatially-complete (or gap-filled) directional reflectance retrievals for missing dates of acquisition. This study demonstrates a unique BRDF retrieval capability that may well serve research efforts that seek to evaluate and refine the accuracy of these multisensor data and products. As more campaign datasets become available in the near future, BRDF retrievals from CAR will be used to 
obtain different albedo, angular, and vegetation quantities that are more directly related to surface biophysical properties. In addition to algorithm refinement and validation exercises, these retrievals can be potentially used to characterize the structural dynamics of complex heterogeneous environments, also providing much needed constraints to model interpolations/extrapolations from multisensor surface biophysical datasets obtained at different spatial scales and time periods.

These reference datasets are also needed for studies seeking to identify systematic differences between satellite sensors that may affect the quality and consistency of long-term Earth system data records. For instance, satellite intercomparisons, while useful in pointing out areas of divergence, both in terms of value and quality assurance, cannot establish what products are correct without an independent benchmark that is able to reproduce the wide range of view-angle geometries and retrieval schemes employed by multiple BRDF/albedo datasets (Muller et al., 2007; Geiger et al., 2008; Rutan et al., 2009; Pinty et al., 2010; Taberner et al., 2010). Without an independent mechanism, these assessments will continue to be limited to some verification of the relative performance.

\section{Acknowledgements}

The research reported in this article was supported by the Science Mission Directorate of the National Aeronautics and Space Administration as part of the Earth Observing System, Radiation Sciences Program and Airborne Science Program. We thank the CLASIC Science team (B. Schmidt, M. Miller, P. Lamb, J. Ogren, J. Mather et al.) and Sky Research, J-31 aircraft team (D. Thrasher, S. Kaiser, K. Zimmerer \& R. Billings) for their support during the CLASIC experiment; as well as Dr. Mark J. Chopping (Montclair State University) and three anonymous reviewers, for their valuable comments. The analysis was performed under NASA Grants NNX08AF89G (CKG), NNX07AT35H and NNX08AE94A (CBS); and the U.S. Department of Energy (DOE) Atmospheric Radiation Measurement (ARM) Program under grant DOE-DE-FG02-06ER64178 (CBS).

\section{References}

Armston, J. D., Scarth, P. F., Phinn, S. R., \& Danaher, T. J. (2007). Analysis of multi-date MISR measurements for forest and woodland communities, Queensland, Australia. Remote Sensing of Environment, 107, 287-298. doi:10.1016/j.rse.2006.11.003.

Bacour, C., \& Bréon, F. M. (2005). Variability of biome reflectance directional signatures as seen by POLDER. Remote Sensing of Environment, 98, 80-95. doi:10.1016/j.rse. 2005.06.008.

Bacour, C., Jacquemoud, S., Leroy, M., Hautecoeur, O., Weiss, M., Prévot, L., et al. (2002) Reliability of the estimation of vegetation characteristics by inversion of three canopy reflectance models on airborne polder data. Agronomie: Agriculture and Environment, 22, 555-565. doi:10.1051/agro:2002039.

Bicheron, P., \& Leroy, M. (2000). Bidirectional reflectance distribution function signatures of major biomes observed from space. Journal of Geophysical Research, 105, 26669-26681. doi:10.1029/2000JD900380.

Bindlish, R., Jackson, T., Sun, R., Cosh, M., Yueh, S., \& Dinardo, S. (2009). Combined passive and active microwave observations of soil moisture during CLASIC. IEEE Geoscience and Remote Sensing Letters, 6, 644-648. doi:10.1109/LGRS.2009.2028441.

Brown de Colstoun, E. C., Walthall, C. L., Cialtela, A. T., Vermote, E. R., Halthore, R. N., \& Irons, J. R. (1996). Variability of BRDF with land cover type for the west central HAPEX Sahel super site. Proceedings of the International Geoscience and Remote Sensing Symposium, IGARSS'96. doi:10.1109/IGARSS.1996.516837.

Chen, J. M., Menges, C. H., \& Leblanc, S. G. (2005). Global mapping of foliage clumping index using multi-angular satellite data. Remote Sensing of Environment, 97 447-457. doi:10.1016/j.rse.2005.05.003.

Chen, Y., Liang, S., Wang, J., Kim, H., \& Martonchik, J. V. (2008). Validation of the MISR land surface broadband albedo. International Journal of Remote Sensing, 29, 6971-6989. doi:10.1080/01431160802199876.

Chopping, M., Su, L., Rango, A., Martonchik, J. V., Peters, D. P. C., \& Laliberte, A. (2008) Remote sensing of woody shrub cover in desert grasslands using MISR with geometric-optical canopy reflectance model. Remote Sensing of Environment, 112, 19-34. doi:10.1016/j.rse.2006.04.023.

Chopping, M. J. (2001). Testing LiSK BRDF models over a semi-arid grassland region with visible and near-infrared ATSR-2 and AVHRR data. International Journal of Remote Sensing, 22, 3533-3552. doi:10.1080/01431160010007024.

Chopping, M. J., Rango, A., Havstad, K. M., Schiebe, F. R., Ritchie, J. C., Schmugge, T. J. et al. (2002). Canopy attributes of desert grassland and transition communities derived from multiangular airborne imagery. Remote Sensing of Environment, 85, 339-354. doi:10.1016/S0034-4257(03)00012-9.

Chopping, M. J., Su, L., Rango, A., \& Maxwell, C. (2004). Modelling the reflectance anisotropy of Chihuahuan Desert grass-shrub transition canopy-soil complexes. International Journal of Remote Sensing, 25, 2725-2745. doi:10.1080/01431160310001618437.

Cosh, M. H. (2007). SGP Cloud and Land Surface Interaction Campaign (CLASIC) Land Surface States and Fluxes Experiment Plan. In: Atmospheric Radiation Measurement (ARM) Program.

d'Entremont, R. P., Schaaf, C. B., Lucht, W., \& Strahler, A. H. (1999). Retrieval of red spectral albedo and bidirectional reflectance using AVHRR HRPT and GOES satellite observations of the New England region. Journal of Geophysical Research, 104, 6229-6239. doi:10.1029/1998JD200104.

Diner, D. J., Barge, L. M., Bruegge, C. J., Chrien, T. G., Conel, J. E., Eastwood, M. L., et al. (1998a). Airborne Multi-angle Imaging SpectroRadiometer (AirMISR) - Instrument description and first results. IEEE Transactions on Geoscience and Remote Sensing, 36, 1339-1349. doi:10.1109/36.701083.

Diner, D. J., Beckert, J. C., Reilly, T. H., Bruegge, C. J., Conel, J. E., Kahn, R. A., et al. (1998b). Multi-angle Imaging SpectroRadiometer (MISR) - Instrument description and experiment overview. IEEE Transactions on Geoscience and Remote Sensing, 36, 1072-1087. doi:10.1109/36.700992.

Gao, F., Masek, J., Schwaller, M., \& Hall, F. (2006). On the blending of the Landsat and MODIS surface feflectance: Predicting daily Landsat surface reflectance. IEEE Transactions on Geoscience and Remote Sensing, 44, 2207-2218. doi:10.1109/TGRS. 2006.872081.

Gao, F., Morisette, J. T., Wolfe, R. E., Ederer, G., Pedelty, J., Masuoka, E., et al. (2008). An algorithm to produce temporally and spatially continuous MODIS LAI time series. IEEE Geoscience and Remote Sensing Letters, 5, 60-64. doi:10.1109/LGRS.2007.907971.

Gatebe, C. K., Dubovik, O., King, M. D., \& Sinyuk, A. (2009). Simultaneous retrieval of aerosol and surface optical properties from combined airborne-and ground-based direct and diffuse radiometric measurements. Atmospheric Chemistry and Physics, 10, 2777-2794. doi:10.5194/acpd-9-26491-2009.

Gatebe, C. K., King, M. D., Lyapustin, A. I., Arnold, G. T., \& Redemann, J. (2005). Airborne spectral measurements of ocean directional reflectance. Journal of the Atmospheric Sciences, 62, 1072-1092. doi:10.1175/JAS3386.1.

Gatebe, C. K., King, M. D., Platnick, S., Arnold, G. T., Vermote, E. F., \& Schmid, B. (2003). Airborne spectral measurements of surface-atmosphere anisotropy for several surfaces and ecosystems over southern Africa. Journal of Geophysical Research, 108 (D13). doi:10.1029/2002JD002397.

Geiger, B., Carrer, D., Franchistéguy, L., Roujean, J. L., \& Meurey, C. (2008). Land surface albedo derived on a daily basis from Meteosat second generation observations. IEEETransactions on Geoscience and Remote Sensing, 46, 3841-3856. doi:10.1109/TGRS.2008.2001798.

GeoEye (2006). IKONOS Imagery Products Guide Version 1.5. In. Dulles, VA.

Georgiev, G. T., Gatebe, C. K., Butler, J. J., \& King, M. D. (2009). BRDF analysis of savanna vegetation and salt-pan samples. IEEE Transactions on Geoscience and Remote Sensing, 47, 2546-2556. doi:10.1109/TGRS.2009.2021331.

Gobron, N., Pinty, B., Verstraete, M. M., Widlowski, J. -L., \& Diner, D. (2002). Uniqueness of multiangular measurements-Part II: Joint retrieval of vegetation structure and photosynthetic activity from MISR. IEEE Transactions on Geoscience and Remote Sensing, 40, 1574-1592. doi:10.1109/TGRS.2002.801147.

Goutorbe, J. -P., Lebel, T., Tinga, A., Bessemoulin, P., Brouwer, J., Dolman, A. J., et al. (1994). HAPEX-Sahel: a large-scale study of land-atmosphere interactions in the semi-arid tropics. Annales Geophysicae, 12, 53-64. doi:10.1007/s00585-994-0053-0.

Hautecoeur, O., \& Leroy, M. M. (1998). Surface bidirectional reflectance distribution function observed at global scale by POLDER/ADEOS. Geophysical Research Letters, 25, 4197-4200. doi:10.1029/1998GL900111.

Heathman, G. C., Larose, M., Cosh, M. H., \& Bindlish, R. (2009). Surface and profile soil moisture spatio-temporal analysis during an excessive rainfall period in the Southern Great Plains, USA. CATENA, 78, 159-169. doi:10.1016/j.catena.2009.04.002.

Hill, M. J., Averill, C., Jiao, Z., Schaaf, C. B., \& Armston, J. D. (2008). Relationship of MISR RPV parameters and MODIS BRDF shape indicators to surface vegetation patterns in an Australian tropical savanna. Canadian Journal of Remote Sensing, 34, S247-S267. doi: $10.5589 / \mathrm{m} 08-042$.

Holben, B. N., Eck, T. F., Slutsker, I., Tanré, D., Buis, J. P., Setzer, A., et al. (1998). AERONET-A federated instrument network and data archive for aerosol characterization. Remote Sensing of Environment, 66, 1-16. doi:10.1016/S0034-4257(98) 00031-5.

Huete, A., Didan, K., Miura, T., Rodriguez, E. P., Gao, X., \& Ferreira, L. G. (2002). Overview of the radiometric and biophysical performance of the MODIS vegetation indices. Remote Sensing of Environment, 83, 195-213. doi:10.1016/S0034-4257(02)00096-2.

Jin, Y., Schaaf, C. B., Gao, F., Li, X., Strahler, A. H., Bruegge, C., et al. (2002). Improving MODIS surface BRDF/Albedo retrieval with MISR multi-angle observations. IEEE Transactions on Geoscience and Remote Sensing, 40, 1593-1604. doi:10.1109/TGRS. 2003.815674

Jin, Y. F., Schaaf, C. B., Gao, F., Li, X. W., Strahler, A. H., Lucht, W., et al. (2003a). Consistency of MODIS surface bidirectional reflectance distribution function and albedo retrievals: 1. Algorithm performance. Journal of Geophysical Research, 108, D5. doi:10.1029/2002JD002803.

Jin, Y. F., Schaaf, C. B., Woodcock, C. E., Gao, F. Li, X. W., Strahler, A. H., et al. (2003b). Consistency of MODIS surface bidirectional reflectance distribution function and albedo retrievals: 2. Validation. Journal of Geophysical Research, 108, D5. doi: 10.1029/2002JD002804

Johnson, L. F. (1994). Multiple view zenith angle observations of reflectance from ponderosa pine stands. International Journal of Remote Sensing, 15, 3859-3865. doi: 10.1080/01431169408954365.

King, M. D., Menzel, W. P., Grant, P. S., Myers, J. S., Arnold, G. T., Platnick, S. E., et al. (1996). Airborne scanning spectrometer for remote sensing of cloud, aerosol, water 
vapor and surface properties. Journal of Atmospheric and Oceanic Technology, 13, 777-794.

King, M. D., Strange, M. G., Leone, P., \& Blaine, L. R. (1986). Multiwavelength scanning radiometer for airborne measurements of scattered radiation within clouds. Journal of Atmospheric and Oceanic Technology, 3, 513-522.

Knobelspiesse, K. D., Cairns, B., Schmid, B., Román, M., \& Schaaf, C. B. (2008). Surface BRDF estimation from an aircraft compared to MODIS and ground estimates at the Southern Great Plains site. Journal of Geophysical Research-Atmospheres, 113, D20. doi:10.1029/2008JD010062.

Kotchenova, S. Y., Vermote, E. F., Matarrese, R., \& Klemm, F. J. (2006). Validation of a vector version of the $6 \mathrm{~S}$ radiative transfer code for atmospheric correction of satellite data. Part I: Path Radiance. Applied Optics, 45, 6726-6774. doi:10.1364/ A0.45.006762.

Lacaze, R., Chen, J. M., Roujean, J. -L., \& Leblanc, S. G. (2002). Retrieval of vegetation clumping index using hot spot signatures measured by POLDER instrument. Remote Sensing of Environment, 79, 84-95. doi:10.1016/S00344257(01)00241-3.

Leroy, M., Deuzé, J. L., Bréon, F. M., Hautecoeur, O., Herman, M., Buriez, J. C., et al. (1997). Retrieval of atmospheric properties and surface bidirectional reflectances over land from POLDER/ADEOS. Journal of Geophysical Research, 102, 17023-17037. doi: 10.1029/96JD02662.

Lewis, P. (1995). The utility of kernel-driven BRDF models in global BRDF and albedo studies. Proceedings of the International Geoscience and Remote Sensing Symposium, IGARSS'95, 1186-1188. doi:10.1109/IGARSS.1995.521179.

Li, X., Gao, F., Wang, J., \& Strahler, A. H. (2001). A priori knowledge accumulation and its application to linear BRDF model inversion. Journal of Geophysical Research, 106, 11925-11935. doi:10.1029/2000JD900639.

Li, X. W., \& Strahler, A. H. (1992). Geometric-optical bidirectional reflectance modeling of the discrete crown vegetation canopy - Effect of crown shape and mutual shadowing. IEEE Transactions on Geoscience and Remote Sensing, 30, 276-292. doi: 10.1109/36.134078.

Liang, S., Fang, H. L., Chen, M. Z., Shuey, C. J., Walthall, C., Daughtry, C., et al. (2002). Validating MODIS land surface reflectance and albedo products: methods and preliminary results. Remote Sensing of Environment, 83, 149-162. doi:10.1016/ S0034-4257(02)00092-5.

Liu, J., Schaaf, C. B., Strahler, A. H., Jiao, Z., Shuai, Y., Zhang, Q., et al. (2009). Validation of Moderate Resolution Imaging Spectroradiometer (MODIS) albedo retrieval algorithm: Dependence of albedo on solar zenith angle. Journal of Geophysical Research-Atmospheres, 114, D01106. doi:10.1029/2008JD009969.

Lucht, W., Schaaf, C. B., \& Strahler, A. H. (2000). An algorithm for the retrieval of albedo from space using semi-empirical BRDF models. IEEE Transactions on Geoscience and Remote Sensing, 38, 977-998. doi:10.1109/36.841980.

Lyapustin, A., Gatebe, C. K. Kahn, R., Brandt, R., Redemann, J., Russell, P., et al. (2010). Analysis of snow BRF from ARCTAS Spring-2008 campaign. Atmospheric Chemistry and Physics, 4359-4375. doi:10.5194/acp-10-4359-2010.

Martonchik, J., Bruegge, C., \& Strahler, A. H. (2000). A Review of Reflectance Nomenclature Used in Remote Sensing. Remote Sensing Reviews, 19, 9-20. doi: $10.1080 / 02757250009532407$.

Moody, E. G., King, M. D., Schaaf, C. B., \& Platnick, S. (2008). MODIS-derived spatially complete surface albedo products: Spatial and temporal pixel distribution and zonal averages. Journal of Applied Meteorology and Climatology, 47, 2879-2894. doi: 10.1175/2008JAMC1795.1.

Muller, J. -P., Preusker, R., Fischer, J., Zuhlke, M., Brockmann, C., \& Regner, P. (2007). ALBEDOMAP: MERIS land surface albedo retrieval using data fusion with MODIS BRDF and its validation using contemporaneous EO and in situ data products. Proceedings of the International Geoscience and Remote Sensing Symposium, IGARSS'07, 2404-2407. doi:10.1109/IGARSS.2007.4423326.

NRSA (2003). IRS-P6 (AWIFS) Data User's Handbook. In G.o.I. Department of Space (Ed.) (p. 142): National Remote Sensing Agency.

Pelgrum, H., Schmugge, T., Rango, A., Ritchie, J., \& Kustas, W. (2000). Length scale analysis of surface albedo, temperature and NDVI in a desert grassland. Water Resources Research, 36, 1757-1765. doi:10.1029/2000WR900028.

Pinty, B., Taberner, M., Haemmerle, V. R., Paradise, S. R., Vermote, E., Verstraete, M., et al. (2010). Global scale comparison of MISR and MODIS land surface albedos. Journal of Climate. doi:10.1175/2010JCLI3709.1.

Pinty, B., Widlowski, J. -L., Gobron, N., Verstraete, M. M., \& Diner, D. J. (2002). Uniqueness of multiangular measurements - Part I: An indicator of subpixel surface heterogeneity from MISR. IEEE Transactions on Geoscience and Remote Sensing, 40 , 1560-1573. doi:10.1109/TGRS.2002.801148.

Privette, J. L., Asner, G. P., Conel, J., Huemmrich, F. K., Olson, R., Rango, A., et al. (2000). The EOS prototype validation exercise (PROVE) at Jornada - Overview and lessons learned. Remote Sensing of Environment, 74, 1-12. doi:10.1016/S0034-4257(00) 00117-6.

Privette, J. L., Eck, T. F., \& Deering, D. W. (1997). Estimating spectral albedo and nadir reflectance through inversion of simple BRDF models with AVHRR/ MODIS-like data. Journal of Geophysical Research, 102, 29529-29542. doi: 10.1029/97JD01215.

Privette, J. L., Emery, W. J., \& Schimel, D. S. (1996). Inversion of a vegetation reflectance model with NOAA AVHRR data. Remote Sensing of Environment, 58, 187-200. doi: 10.1016/S0034-4257(96)00066-1.

Privette, J. L., Tian, Y., Roberts, G., Scholes, R. J., Wang, Y., Caylor, K., et al. (2004). Vegetation structure characteristics and relationships of Kalahari woodlands and savannas. Global Change Biology, 10, 281-291. doi:10.1111/j.1365-2486.2004.00740.x.

Qin, W., \& Gerstl, S. A. W. (2000). 3-D scene modeling of Jornada semi-desert vegetation cover and its radiation regime. Remote Sensing of Environment, 74, 145-165. doi: 10.1016/S0034-4257(00)00129-2.
Román, M. O., Schaaf, C. B., Lewis, P., Gao, F., Anderson, G. P., Privette, J. L., et al. (2010). Assessing the coupling between surface albedo derived from MODIS and the fraction of diffuse skylight over spatially-characterized landscapes. Remote Sensing of Environment, 114, 738-760. doi:10.1016/j.rse.2009.11.014.

Román, M. O., Schaaf, C. B., Yang, X., Woodcock, C. E., Strahler, A. H., Braswell, R. H., et al (2009). The MODIS (Collection V005) BRDF/albedo product: Assessment of spatial representativeness over forested landscapes. Remote Sensing of Environment, 113, 2476-2498. doi:10.1016/j.rse.2009.07.009.

Ross, J. (1981). The Radiation Regime and Architecture of Plant Stands. The Hague Norwell, Mass: Dr. W. Junk Publishers ISBN 906193-607-1.

Roujean, J., Leroy, M., \& Deschanms, P. (1992). A bidirectional reflectance model of the Earth's surface for the correction of remote sensing data. Journal of Geophysical Research, 97, 20,455-420,468. doi:10.1029/92JD01411.

Roy, D. P., Ju, J., Lewis, P., Schaaf, C. B., Gao, F., Hansen, M., et al. (2008). Multi-temporal MODIS-Landsat data fusion for relative radiometric normalization, gap filling, and prediction of Landsat data. Remote Sensing of Environment, 112, 3112-3130. doi: 10.1016/j.rse.2008.03.009.

Russell, C. A., Irons, J. R., \& Dabney, P. W. (1997). Bidirectional reflectances of selected BOREAS sites from multiangle airborne data. Journal of Geophysical Research, 102 (D24), 25,505-529,516. doi:10.1029/96JD03880.

Russell, P. B., Livingston, J. M., Hignett, P., Kinne, S., Wong, J., Chien, A., et al. (1999) Aerosol-induced radiative flux changes off the United States mid-Atlantic coast: Comparison of values calculated from sunphotometer and in situ data with those measured by airborne pyranometer. Journal of Geophysical Research, 104 2289-2308. doi:10.1029/1998JD200025.

Rutan, D., Rose, F. G., Román, M., Manalo-Smith, N., Schaaf, C., \& Charlock, T. (2009). Development and assessment of broadband surface albedo from CERES clouds and radia-tion swath data product. Journal of Geophysical Research, 114, D08125. doi: 10.1029/2008JD010669.

Salomon, J. G., Schaaf, C. B., Strahler, A. H., Gao, F., \& Jin, Y. F. (2006). Validation of the MODIS bidirectional reflectance distribution function and albedo retrievals using combined observations from the Aqua and Terra platforms. IEEE Transactions on Geoscience and Remote Sensing, 44, 1555-1565. doi:10.1109/TGRS. 2006.871564

Sandmeier, S., Muller, C., Hosgood, B., \& Andreoli, G. (1998). Physical mechanisms in hyperspectral BRDF data of grass and watercress. Remote Sensing of Environment, 66, 222-233. doi:10.1016/S0034-4257(98)00060-1.

Schaaf, C. B., Gao, F., Strahler, A. H., Lucht, W., Li, X., Tsang, T., et al. (2002). First operational BRDF, albedo and nadir reflectance products from MODIS. Remote Sensing of Environment, 83, 135-148. doi:10.1016/S0034-4257(02)00091-3.

Schaaf, C. B., Liu, J., Gao, F., \& Strahler, A. H. (2011). MODIS albedo and reflectance anisotropy products from Aqua and Terra. In B. Ramachandran, C. Justice, \& M Abrams (Eds.), Land Remote Sensing and Global Environmental Change: NASA's Earth Observing System and the Science of ASTER and MODIS (p. 873): Springer-Verlag. ISBN:1441967486.

Schaaf, C. B., Martonchik, J., Pinty, B., Govaerts, Y., Gao, F., Lattanzio, A., et al. (2008). Retrieval of surface albedo from satellite sensors. In S. Liang (Ed.), Advances in Land Remote Sensing: System, Modeling, Inversion and Application (pp. 219-243): Springer.

Schaepman-Strub, G., Schaepman, M. E., Painter, T. H., Dangel, S., \& Martonchik, J. V. (2006). Reflectance quantities in optical remote sensing-definitions and case studies. Remote Sensing of Environment, 103, 27-42. doi:10.1016/j.rse.2006.03.002.

Sellers, P. J., Hall, F. G., Asrar, G., Strebel, D. E., \& Murphy, R. E. (1988). The first ISLSCP field experiment (FIFE). Bulletin of the American Meteorological Society, 69, 22-27.

Sellers, P. J., Hall, F. G., Asrar, G., Strebel, D. E., \& Murphy, R. E. (1992). An overview of the First International Satellite Land Surface Climatology Project (ISLSCP) Field Experiment (FIFE). Journal of Geophysical Research, 97, 18,345-341,8371. doi: 10.1029/92JD02111.

Strugnell, N., Lucht, W., \& Schaaf, C. B. (2001). A global albedo data set derived from AVHRR data for use in climate simulations. Geophysical Research Letters, 28, 191-194. doi:10.1029/2000GL011580.

Su, L., Chopping, M. J., Rango, A., Martonchik, J. V., \& Peters, D. P. C. (2007). Support vector machines for recognition of semi-arid vegetation types using MISR multiangle imagery. Remote Sensing of Environment, 107, 299-311. doi:10.1016/j. rse.2006.05.023.

Susaki, J., Yasuoka, Y., Kajiwara, K., Honda, Y., \& Hara, K. (2007). Validation of MODIS albedo products of paddy fields in Japan. IEEE Transactions on Geoscience and Remote Sensing, 45, 206-217. doi:10.1109/TGRS.2006.882266.

Swap, R. J., Annegarn, H. J., \& Otter, L. (2002). Southern African Regional Science Initiative (SAFARI 2000): Summary of science plan. South African Journal of Science, 98, 119-124.

Taberner, M., Pinty, B., Govaerts, Y., Liang, S., Verstraete, M. M., Gobron, N., et al. (2010). Comparison of MISR and MODIS land surface albedos: Methodology. Journal of Geophysical Research, 115. doi:10.1029/2009JD012665.

Trishchenko, A., Luo, Y., Li, Z., Park, W., \& Khlopenkov, K. (2005). Spectral, temporal and spatial properties of surface BRDF/Albedo over the ARM SGP area from multi-year satellite observations. Proceedings of the Fifteenth Atmospheric Radiation Measurement (ARM) Science Team Meeting.

Tucker, C. J. (1979). Red and photographic infrared linear combinations for monitoring vegetation. Remote Sensing of Environment, 8, 127-150. doi:10.1016/0034-4257 (79)90013-0.

Vermote, E. F., Tanré, D., Deuze, J. L., Herman, M., \& Morcrette, J. -J. (1997). Second Simulation of the Satellite Signal in the Solar Spectrum, 6S: an overview Geoscience and Remote Sensing. IEEE Transactions on Geoscience and Remote Sensing, 35, 675-686. doi:10.1109/36.581987. 
Walthall, C., Roujean, J. -L., \& Morisette, J. (2000). Field and landscape BRDF optical wavelength measurements: Experience, techniques and the future. Remote Sensing Reviews, 18, 503-531. doi:10.1080/02757250009532399.

Wanner, W., Li, X., \& Strahler, A. H. (1995). On the Derivation of Kernels for KernelDriven Models of Bidirectional Reflectance. Journal of Geophysical Research, 100, 21077-21089. doi:10.1029/95JD02371.

Wanner, W., Strahler, A. H., Hu, B., Lewis, P., Muller, J., Li, X., et al. (1997). Global retrieval of bidirectional reflectance and albedo over land from EOS MODIS and MISR data: Theory and algorithm. Journal of Geophysical Research, 102 17143-17161. doi:10.1029/96JD03295.

Waring, R. H., \& Peterson, D. L. (1994). Oregon Transect Ecosystem Research (OTTER) Project. Ecological Applications, 4, 210-211. doi:10.2307/1941927.
Widlowski, J. -L., Pinty, B., Gobron, N., Verstraete, M., \& Davis, A. B. (2001). Characterization of surface heterogeneity detected at the MISR/TERRA subpixel scale. Geophysical Research Letters, 28, 4639-4642. doi:10.1029/2001GL013490.

Widlowski, J. L., Pinty, B., Lavergne, T., Verstraete, M. M., \& Gobron, N. (2005). Using 1-D models to interpret the reflectance anisotropy of 3-D canopy targets: issues and caveats. IEEE Transactions on Geoscience and Remote Sensing, 43, 2008-2017. doi: 10.1109/TGRS.2005.853718.

Zhang, O. (2008). A Global Spatially and Temporarily Complete Reflectance Anisotropy Database to Improve Surface Characterization for Albedo Modeling. In, PhD Thesis, Department of Geography and Environment (p. 155). Boston, MA: Boston University. 